\title{
Observations and environmental implications of variability in the vertical turbulent mixing in Lake Simcoe
}

\author{
Mijanur R. Chowdhury, Mathew G. Wells, Remo Cossu \\ Version Accepted Manuscript \\ Citation Chowdhury, M.R., Wells, M.G., Cossu, R., 2015. Observations and \\ (published version) environmental implications of variability in the vertical turbulent mixing \\ in Lake Simcoe. J. Great Lakes Res. 41. \\ https://doi.org/10.1016/j.jglr.2015.07.008 \\ Copyright/License \\ (c) (1) $\fallingdotseq$ This work is licensed under the Creative Commons \\ BY NC ND Attribution-NonCommercial-NoDerivatives 4.0 \\ International License. To view a copy of this license, visit \\ http://creativecommons.org/licenses/by-nc-nd/4.0/.
}

How to cite TSpace items

Always cite the published version, so the author(s) will receive recognition through services that track citation counts, e.g. Scopus. If you need to cite the page number of the author manuscript from TSpace because you cannot access the published version, then cite the TSpace version in addition to the published version using the permanent URI (handle) found on the record page.

This article was made openly accessible by $U$ of $T$ Faculty. Please tell us how this access benefits you. Your story matters. 
1

2

3

\title{
Observations and environmental implications of variability in the vertical turbulent mixing in Lake Simcoe.
}

\author{
Mijanur R. Chowdhury*, Mathew G. Wells, and Remo Cossu \\ Physical and Environmental Sciences, University of Toronto Scarborough \\ Toronto, ON, Canada
}

Date of Submission: March 10, 2014

\section{*Corresponding author}

Dr. Mijanur R. Chowdhury

Dept. of Physical \& Environmental Sciences

University of Toronto Scarborough

1265 Military Trail, Toronto, ON M1C 1A4, Canada

Email: mijanur.chowdhury@utoronto.ca 


\begin{abstract}
A field study was conducted in the stratified waters of Lake Simcoe to examine variations in turbulent mixing rates for a 40-day period in late summer. High sampling frequency records of water currents were acquired using an Acoustic Doppler Current Profiler (ADCP) and the data were processed using the variance method to quantify vertical eddy diffusivity, $K_{z}$. Internal turbulent mixing in the thermally stratified waters of Lake Simcoe exhibited large spatial and temporal variability with frequent high values of $K_{z}$ in the epilimnion $\left(K_{z} \sim 10^{-4}-10^{-3} \mathrm{~m}^{2} \mathrm{~s}^{-1}\right)$ and relatively low values in the metalimnion $\left(K_{z} \sim 10^{-6}-10^{-5} \mathrm{~m}^{2} \mathrm{~s}^{-1}\right)$ and the hypolimnion $\left(K_{z} \sim 10^{-5}\right.$ $\left.\mathrm{m}^{2} \mathrm{~s}^{-1}\right)$. The spatio-temporal variability of quantified $K_{z}$ has been characterized by the dimensionless gradient Richardson number, $R i_{g}$ and Lake number, $L_{N}$ which calculate the relative strengths of the stratification in relation to the velocity shear for the former and the wind forcing for the later. The environmental implications of $K_{z}$ variability on Lake Simcoe are analyzed. We estimate that vertical turbulent transport of dissolved oxygen was $10 \%$ of the total oxygen depleted in the hypolimnion for the observation period. We conclude that at least some of the observed year-to-year variability of hypolimnetic oxygen depletion may be due to the variation in turbulent transport of dissolved oxygen across the thermocline. We also compare the turbulence timeseries to estimates of $K_{z}$ made applying the Thorpe-scale method on measurements from a chain of thermistor loggers and discuss their potential usefulness for longterm environmental monitoring of stratified lakes.
\end{abstract}

Keywords: dimictic lake; thermal stratification, turbulent mixing; the variance method; the Thorpe-scale method; ADCP. 


\section{INTRODUCTION}

Quantifying the extent of vertical internal turbulent mixing rates in a lake has significant environmental implications; especially in analyzing hypolimnetic dissolved oxygen (DO) depletion (Bouffard et al., 2013;2014; Loewen et al., 2007) and distributions of nutrients and primary producers in the lake (MacIntyre, 1998; Wüest and Lorke, 2003; Yeates and Imberger, 2003). For example, the turbulent transport rate of DO from the well-oxygenated epilimnion to the hypolimnion is determined by $F_{t h}=-K_{z t h} \partial \mathrm{DO} / \partial z$ (where $K_{z t h}$ is the vertical turbulent diffusivity, $K_{z}$ at the thermocline), so is directly related to the magnitude of turbulent diffusivity which is often orders of magnitude higher than the molecular diffusion. During periods of strong stratification, the thermocline can act as a barrier to the vertical transport of DO from the surface waters, and increases the likelihood of low DO in the hypolimnion (Bouffard et al., 2013). The variability of $K_{z}$ in both space and time as a function of the external environmental forcing has not been extensively studied for Lake Simcoe, which is a large dimictic lake located in the province of Ontario, Canada. It is important to determine its vertical turbulent mixing rates, as this lake experiences significant summer hypolimnetic DO depletion (see Winter et al., 2007; Young et al., 2011). While there has been considerable effort to determine the role of nutrient loading in determining end of summer DO levels (Nürnburg et al., 2012a; Young et al., 2011), it is not known how potentially large are the turbulent DO fluxes across the thermocline in Lake Simcoe during the strongly stratified summer season. In this manuscript, we present observations on the intermittent behavior of $K_{z}$ for a 40-day period during the summer stratified period for Lake Simcoe. While a number of studies (e.g., MacIntyre et al., 1999; Bouffard et al. 2012; Schwalb et al., 2013) have quantified $K_{z}$ in North American lakes from temperature microstructure measurements, these studies rarely exceeded a few days in duration as use of the microstructure equipment is laborious and requires a dedicated vessel. A recent standard technique to quantify $K_{z}$ in the ocean and estuaries is to process current data acquired by an Acoustic Doppler Current Profiler (ADCP) by a variety of methods including the inertial dissipation (Lorke and Wüest, 2005), the structure function (Wiles et al., 2006), and the variance (Simpson et al., 2005; Stacey et al., 1999a; 1999b) methods in the ocean and in estuaries. In this study, we employ an upward-looking bottom-mounted ADCP to quantify $K_{z}$ in Lake Simcoe employing the variance method. We also study the feasibility of employing thermistor loggers for long-term monitoring ( $\sim 5-6$ months) of $K_{z}$ in a stratified lake. 

were made assuming the transport of DO across the thermocline is insignificant (e.g., Gudimov et al., 2012; Snodgrass and Holubeshen, 1993). However, past observations in the Great Lakes have shown that there can be significant vertical turbulent transport of DO that would play a counteracting role in the hypolimnetic DO depletion rate in Lake Simcoe. For example, two recent studies (Bouffard et al., 2013; Rao et al., 2008) observed that vertical turbulent mixing plays significant role in the oxygen distribution in Lake Erie. Bouffard et al. (2013) estimated that vertical turbulent DO flux across the thermocline replenished $\sim 18 \%$ of the total oxygen depleted in the hypolimnion over the stratified period, while in an earlier study, Snodgrass (1977) estimated it was $\sim 20 \%$ for Lake Ontario. Hence one of the motivations of this study is to analyze the role of vertical turbulent transport of DO on counteracting the hypolimnetic DO depletion in Lake Simcoe during our observation period.

While there has been considerable interest in the water quality of Lake Simcoe, including studies of nutrient fluxes (see Nürnburg et al., 2012a; 2012b), the dynamics of the basin scale internal waves (see Bouffard and Boegman, 2011), and measuring changes in seasonal temperature stratification (see Stainsby et al., 2011), only two recent field studies reported direct measurements of $K_{z}$ in the lake. Cossu and Wells (2013) reported $K_{z}$ values generated by the interaction of large amplitude internal seiches with the sloping boundary. They observed that during periods of upwelling, turbulence at benthic boundary layer was characterized by high turbulent mixing with turbulent diffusivity, $K_{z}=10^{-4} \mathrm{~m}^{2} \mathrm{~s}^{-1}$, whereas periods of down-welling were characterized by reduced mixing and high stratification. Using microstructure measurements during late summer stratification, Schwalb et al. (2013) observed $K_{z} \sim 10^{-5}-10^{-4}$ $\mathrm{m}^{2} \mathrm{~s}^{-1}$ in the less stratified regions of the epilimnion and the hypolimnion and $K_{z} \sim 10^{-6} \mathrm{~m}^{2} \mathrm{~s}^{-1}$ in the strongly stratified metalimnion. Based on the observations in other dimictic lakes (see the review paper of Wüest et al., 2003), it is expected that $\left\langle K_{z}\right\rangle$ is high in the epilimnion which remains nearly isothermal in the summers and hence, the buoyancy forces that might constrain vertical motions are very small. In contrast, there are only limited forces trying that cause mixing when the water is strongly stratified in the metalimnion and the hypolimnion, such as the degeneration of basin scale waves due to shear driven mixing. For example direct measurement of $K_{z}$ in Lake Kinneret by Yeates and Imberger (2003) showed that $K_{z}$ was in the range of $10^{-3}$ - 
$10^{-5} \mathrm{~m}^{2} \mathrm{~s}^{-1}$ in the epilimnion, approximately $10^{-5} \mathrm{~m}^{2} \mathrm{~s}^{-1}$ in the metalimnion and $10^{-7} \mathrm{~m}^{2} \mathrm{~s}^{-1}$ in the hypolimnion.

Measuring $K_{z}$ in any water body is challenging and requires state-of-the-art fast-response equipments, particularly because turbulence acts in very small temporal and spatial scales. In this paper we will discuss observations from a bottom-mounted ADCP to acquire velocity data, which were then processed using the variance method that employs the variance of the opposing beam velocities to estimate $K_{z}$. The variance method, first proposed by Lohrman et al. (1990) and then described in detail subsequently by Stacey et al. (1999a) and Lu and Lueck (1999), has become a standard method to quantify vertical mixing coefficients in bays, oceans, and estuaries for extended time periods (see Rippeth et al., 2002, 2003; Williams and Simpson, 2004). However, it has not been used to quantify turbulent mixing in a low energy limnic environment yet. In addition, inspired by the recent results of van Haren et al., (2012) on the measurements of $K_{z}$ using custom-made thermistor loggers in the ocean, we used a chain of commercially available thermistor loggers to attempt to quantify $K_{z}$ using the so-called Thorpe-scale method (Thorpe, 1977). The purpose of using thermistor loggers was to study the usefulness of using them for long-term monitoring ( $\sim 6$ months) of $K_{z}$ by comparing their resolving capability with the standard approach of using ADCP. The Thorpe-scale method estimates $K_{z}$ from the number and magnitude of density inversions which can be calculated from the high-resolution density or temperature profiles. In addition to these above-mentioned two robust methods mentioned above, we have also applied the heat-budget method (Jassby and Powell, 1975) to compare the estimates of $K_{z t h}$.

In this study, we have also analyzed the correlation of the variability of $K_{z}$ values with the wind speed and duration, which are the main driving force for the vertical turbulent mixing in Lake Simcoe during summer stratification. The relative strength of the wind forcing in relation to the stratification is quantified by the dimensionless Lake number, $L_{N}$ (Imberger and Patterson, 1990; Robertson and Imberger, 1990). A number of past studies (e.g., MacIntyre et al., 1999; Read et al., 2011) observed that for $L_{N}<1$, the potential of increased diapycnal mixing across the metalimnion increases. We discuss the variability in $K_{z}$ values with $L_{N}$ for our observation period in Lake Simcoe. Another way to parse out the contribution of wind forcing is to characterize $K_{z}$ with the dimensionless gradient Richardson number, $R i_{g}$ which quantifies the relative strength 
wind-induced vertical current shear in relation to the stabilizing effect of the stratification (Pernica et al., 2014). A number of parameterizations of $K_{z}$ as a function of $R i_{g}$ are available in the literature and frequently used in the analysis of turbulent mixing when direct measurement of $K_{z}$ is not available (see Bouffard et al., 2013; Loewen et al., 2007; Rao et al., 2008). The simultaneous measurements of current, stratification, and vertical diffusion coefficients have allowed us to check three such parameterizations and to discuss their applicability to Lake Simcoe.

This manuscript addresses the question of how turbulent mixing varies in space and time in Lake Simcoe in the following sections. We start with a description of the field site. The details of the instrumentation that were deployed in the field study and data analysis techniques to process the acquired data are described in the following section. Then, we summarize the observations of current, stratification, and turbulence estimates from the variance method. The variability of $K_{z}$ as a function of space and time is then related to the variations in wind speed. We relate the spatial and temporal variability of $K_{z}$ with the $R i_{g}$ and $L_{N}$. We discuss the environmental implications of the turbulent transport of DO on the hypolimnetic oxygen depletion and the mixing time scales. We then compare the estimates of $K_{z}$ made from the thermistor chain with the estimates from the ADCP, and discuss the potential usefulness of thermistor loggers for long-term monitoring of stratified lakes.

\section{STUDY SITE}

Lake Simcoe is located at $44^{\circ} 25^{\prime} \mathrm{N}, 79^{\circ} 30^{\prime} \mathrm{W}$ and is the sixth largest inland lake of Ontario. The lake, with total surface area of $722 \mathrm{~km}^{2}$ and total volume of $11.6 \mathrm{~km}^{3}$, is composed of one main basin with two side arms; in the west is Kempenfelt Bay and in the southwest is Cook's Bay (Fig. 1). The main basin is roughly circular with a gentle sloping shallow eastern half, and steep slopes on the western side. The field site is located on the south-eastern shore of the main basin where there is a gentle slope of approximately $1.5 \mathrm{~m}$ per $\mathrm{km}$. The lake has a maximum depth of $41 \mathrm{~m}$, with a mean depth of $20 \mathrm{~m}$ and a maximum effective fetch of $30 \mathrm{~km}$ (Fig. 1). The lake is dimictic, with a mean thermocline depth of $10 \mathrm{~m}$, and typical summer water temperatures reach $20-22^{\circ} \mathrm{C}$ in the epilimnion and $8-10^{\circ} \mathrm{C}$ in the hypolimnion (Stainsby et al., 2011). 


\section{Instrumentation and Data Acquisition}

\section{METHODS}

A long vertical thermistor chain was deployed at the field site (located at $44^{\circ} 22.4^{\prime} \mathrm{N}$ $79^{\circ} 22.98^{\prime}$ W, see Fig. 1) at a depth of $20 \mathrm{~m}, 5 \mathrm{~km}$ from the southern shoreline of Lake Simcoe from day of year (DOY) 215 to 258 ( $3^{\text {rd }}$ of August until $15^{\text {th }}$ of September) of 2011 . The chain consisted of 16 individual temperature loggers (TR-1060, RBR), with a vertical spacing of $1 \mathrm{~m}$ between 4.65 and $19.65 \mathrm{~m}$ depth. The loggers had an accuracy of $0.002{ }^{\circ} \mathrm{C}$ and the sampling interval was $4 \mathrm{~s}$. They were factory calibrated immediately before the field deployment. Velocity data were collected using a $600-\mathrm{kHz}$ ADCP, manufactured by RD Instruments (RDI), rigidly mounted on a benthic tripod at $20 \mathrm{~m}$ depth near the thermistor chain (Fig. 1). The upward looking ADCP recorded velocities of the 4 beams in beam coordinates in Mode 1 (default setting) every 4 seconds with a fast ping rate (55 pings per ensemble) in bins of $1 \mathrm{~m}$ starting from $2.3 \mathrm{~m}$ above the lake bottom. Using RD Instruments specification (from RDI PlanADCP configuration software), we estimated the uncertainty in our instantaneous measured velocities as $\sigma_{N}=0.006 \mathrm{~ms}^{-1}$. Details of the instrumentations and data used in the study are summarized in Table 1.

All data presented here start at the DOY 216 (0:00 on August 4) approximately 8-12 h after the instruments were deployed in the water and finish at the DOY 257 of 2011. The deployed location is $1 \mathrm{~km}$ north of the long term Ontario Ministry of the Environment (OMOE) monitoring site S15 $\left(44^{\circ} 21.86^{\prime} \mathrm{N} 79^{\circ} 23.27^{\prime} \mathrm{W}\right)$. OMOE have been measuring water temperature and DO at the S15 approximately every two weeks during the ice free season from May to October since 1980 (Eimers et al., 2005; Stainsby et al., 2011). These measurements were made at 1-m depth intervals with a hand-held YSI probe. Wind speed, wind direction and air temperature for our observation period were obtained from the hourly records by the Lake

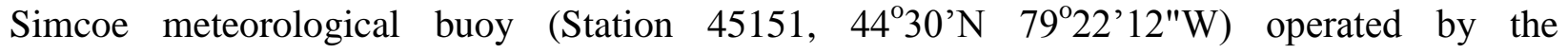
Environment Canada located approximately $15 \mathrm{~km}$ north of our field site (see Fig. 1). We have also used long-term wind data from the North American Regional Reanalysis (NARR) to examine the interannual summer-time variability of the wind speed. The NARR data set is produced for 8 times per day with a horizontal grid spacing of $32 \mathrm{~km}$ over Lake Simcoe by the 

from Mesinger et al. (2006). All wind speed data has been corrected for 10-m measurement height assuming a log-law boundary layer. The acquired temperature, velocity, and wind speed data were processed and analyzed using following methods.

\section{Calculation of the gradient Richardson number, $R i_{g}$}

The relative strengths of the stratification and shear are parameterized by the gradient Richardson number, $R i_{g}$. Turbulence mixing may occur in the areas of stratified waters where $R i_{g}$ is below some critical value of $R i_{c r}$ and for $R i_{g}>R i_{c r}$ mixing occurs due to molecular diffusion. According to theoretical stability analysis, $R i_{c r}$ were found as equal to 0.25 (Miles, 1961), while the suggested value of $R i_{c r}$ from direct measurements ranges 0.25-1 (Large et al., 1994; Kundu and Beardsley, 1991). The gradient Richardson number $\left(R i_{g}\right)$ for the observational period has been calculated as:

$$
R i_{g}=\frac{N^{2}}{S^{2}}
$$

where $N$ is a measure of the stratification often referred to as the buoyancy frequency defined as $N=\left(\frac{g}{\rho_{0}} \frac{\partial \rho}{\partial z}\right)^{1 / 2}$ with $g$ as the gravitational constant, $\rho$ as the density of the water columns, $\rho_{0}=$ $1000 \mathrm{kgm}^{-3}$ as a reference density and $z$ as the depth measured from the surface. The density of the water $(\rho)$ in the water column was computed from the measured temperature using freshwater equation of state (Chen and Millero, 1977). The denominator in Eq. (1) is the vertical current shear defined as $S^{2}=(\partial u / \partial z)^{2}+(\partial v / \partial z)^{2}$ with $u$ and $v$ as the horizontal components of current velocity, which have been calculated from the acquired velocities by ADCP in beam coordinates (Stacey et al., 1999a). Both $N^{2}$ and $S^{2}$ have been calculated using central difference of the mean velocity and density profiles respectively with single-sided estimate at each boundary. A minimum threshold for $N^{2}$ exists that is associated with the smallest density difference resolvable by the two adjacent thermistor loggers in the thermistors chain. Based on the minimum temperature difference resolvable by our two adjacent temperature loggers of $4 \times 10^{-3}{ }^{\circ} \mathrm{C}$ and taking an average apparent thermal expansion coefficient, $\alpha=0.1 \mathrm{~kg} \mathrm{~m}^{-3}{ }^{\circ} \mathrm{C}^{-1}$, the estimated minimum resolvable density difference, $\partial \rho$ with two vertically $1 \mathrm{~m}$-spaced thermistors is 
$\partial \rho \approx \alpha \partial T \sim 10^{-4} \mathrm{Kg} \mathrm{m}^{-3}$. The corresponding minimum resolvable $N^{2}$ is $\sim 10^{-6} \mathrm{~s}^{-2}$. Therefore, we set the threshold of $N^{2}$ as $10^{-6} \mathrm{~s}^{-2}$ and discarded any value less than that.

Several forms of parameterizations of $K_{z}$ as a function of $R i_{g}$ are available in the literature. We compare the estimated $K_{z}$ values from ADCP measurements with three different empirical parameterizations given below:

$$
\begin{gathered}
K_{z}=K_{o}\left(1+3.33 R i_{g}\right)^{-3 / 2} \\
K_{z}=K_{0}\left(1-\frac{R i_{g}^{2}}{R i_{c r}^{2}}\right)^{-3} \\
K_{z}=K_{0}\left(1+\frac{R i_{g}}{R i_{c r}}\right)^{-p}\left(1+\frac{R i_{g}}{R i_{b}}\right)^{-1}
\end{gathered}
$$

All of these three $K_{z}$ parameterizations have originally been proposed for oceanic mixing. Eq. (2.2) is the popular KPP parameterization proposed by Large et al., (1994) and it has been used in the MIT-GCM hydrodynamic model, while Eq. (2.1) proposed by Munk and Anderson (1948) and Eq. (2.3) proposed by Lozovatski et al. (2006) have recently been used to describe internal mixing in Lake Erie (see Loewen et al., 2007; Bouffard et al., 2013). In all of these parameterizations, $K_{o}$ is the value of the eddy diffusivity during neutral conditions. In Eq. (2.3), value of $R i_{b}$ denotes the transition from non-turbulent to turbulent flow and $p$ is a constant. Suggested values of these two parameters by Lozovatski et al. (2006) are: $\mathrm{p}=1$ or $2 / 3$ and $R i_{b}=$ 0.1 or 0.05 , while Bouffard et al. (2013) observed that higher values $\left(R i_{b}=0.15\right.$ and $\left.\mathrm{p}=5 / 3\right)$ should be used in the case of $R i_{g}$ measurement with $1-\mathrm{m}$ bin which is often larger than typical overturning scale.

\section{Calculation of the Lake number, $L_{N}$}

The stabilizing strength of stratification to the destabilizing tendency of the wind stress is parameterized by the Lake number, $L_{N}$. The ratio of these terms determines the Lake number, $L_{N}$, which was first defined by Imberger and Patterson (1990):

$$
L_{N}=\frac{S_{T} z_{t}}{\rho_{0} u_{*}^{2} A_{0}^{1 / 2} z_{v}}
$$


In Eq. (3), $A_{0}$ is the surface area of the lake, and $z_{v}$ is the depth to the center of volume of lake defined as $z_{v}=\int_{0}^{z_{M}} z A_{z} \partial z / \int_{0}^{z_{M}} A_{z} \partial z$ where $z_{M}$ is the maximum depth of the lake and $A_{z}$ is the area of the lake at depth $z . S_{T}$ is the Schmidt stability parameter that represents the total required energy to re-establish isothermal temperature status within a water column. We used the formulation of $S_{T}$ by Idso (1973) as $S_{T}=\frac{g}{A_{0}} \int_{0}^{z_{M}}\left(z-z_{v}\right) \rho_{z} A_{0} \partial z \cdot u_{*}$ is the water friction velocity due to wind stress and it has been estimated from the wind speed, $u_{w}$ using $u_{*}^{2}=\frac{\rho_{a}}{\rho_{0}} C_{D} u_{w}^{2}$ where $C_{D}=1 \times 10^{-3}$ is the drag coefficient and $\rho_{a}=1.3 \mathrm{~kg} \mathrm{~m}^{-3}$ is the density of air. $\mathrm{z}_{t}$ is the depth of the center of the metalimnion which we considered as equal to the depth of the thermocline. We calculated it from the first moment of the density gradient, $z_{t}=\int_{0}^{z_{M}} z \frac{\partial \rho}{\partial z} d z / \int_{0}^{z_{M}} \frac{\partial \rho}{\partial z} d z$ following Patterson et al., (1984). We identified the metalimnion as the region consisting 1-m above and below the thermocline, similar to Pernica et al. (2014). As the cumulative effect of wind speed is more important than the short-bursts of wind speed in causing the mixing in the water column, we applied 12-hour running averages of $u_{w}$ and 1-hour averages of density in calculating hourly $L_{N}($ Cossu and Wells, 2013).

Diapycnal vertical turbulent mixing driven by shear has been shown to correlate inversely with the $L_{N}$, so that with stronger winds there is more mixing, and with increasing stratification there is less mixing. With lower values of $L_{N}$, the potential of increased diapycnal mixing and hence, the vertical fluxes of mass and energy across the metalimnion increases (MacIntyre and Melack, 2009; Read et al., 2011). When $L_{N}$ is less than order 1, surface upwelling of deep water may occur and turbulence is predicted to be enhanced within the lake (Imberger and Patterson, 1990; Coman and Wells, 2012). It was also shown in recent studies that enhanced mixing in the bottom boundary layer occurs when $L_{N}<2$, in Mono Lake (MacIntyre et al., 1999). Based on the analysis of data obtained from a small arctic lake, MacIntyre et al. (2009) made the following observations on mixing. For low $L_{N}\left(L_{N}<1\right)$, horizontal and vertical mixing occur due to the instabilities in the internal wave field and wind-driven upwelling. For intermediate $L_{N}\left(1<L_{N}\right.$ $<10$ ), mixing is caused primarily by the instabilities in the internal wave field and wind-driven upwelling no longer plays a role. For high $L_{N}\left(L_{N}>10\right)$, internal wave mechanism is suppressed 
and the only remaining turbulent process is the deepening of mixed layer because of cooling that may cause vertical exchange of fluxes. We note that in these descriptions, the Lake Number has usually been applied to strongly stratified lakes where winds play the dominant role in determining mixing, and it would not be an appropriate parameter to describe fall overturn in lakes, which is also driven inpart by surface cooling.

We can further parse out the terms defining $L_{N}$ in Eq. (3) to examine what variable has the most effect in causing significant changes of $L_{N}$. As the value of terms $A_{0}, Z_{v}$, and $\rho_{0}$ is constant for our specific case of Lake Simcoe and $u_{*} \sim u_{w}, L_{N}$ will vary depending on the term $\frac{S_{T} z_{t}}{u_{w}^{2}}$. As the thermocline depth and associated Schmidt stability vary slowly over the year, the daily changes in wind speed, $u_{w}$ will have the most effect in causing the significant change in $L_{N}$. For example, keeping other terms constant in Eq. (4), a change from $S_{t}=1000 \mathrm{Kgs}^{-2}$ to $S_{t}=800$ $\mathrm{Kgs}^{-2}$ will reduce the value of $L_{N}$ by $20 \%$, while increasing $u_{w}$ from $3 \mathrm{~ms}^{-1}$ to $5 \mathrm{~ms}^{-1}$ will cause a $64 \%$ reduction in values of $L_{N}$.

The Lake Number has been previously empirically related to the depth-averaged vertical turbulent diffusivity $\left\langle K_{z}\right\rangle$ in the following form:

$$
\frac{<K_{z}>}{K_{m}}=\frac{c}{L_{N}^{d}}
$$

In Eq. (4), $c$ and $d$ are empirical constants and $K_{m}\left(=1.4 \times 10^{-7} \mathrm{~m}^{2} \mathrm{~s}^{-1}\right)$ is the molecular diffusivity of heat. Romero et al. (1998) obtained $c=107$ and $d=1.1$ for Mono Lake (California), while Yeates and Imberger (2003) obtained $c=200$ and $d=1$ for $\left\langle K_{z}\right\rangle$ data of Lake Kinneret, Canning Reservoir, and Mundaring Reservoir. Both studies obtained these values only for the metamlinion.

\section{Estimation of vertical mixing rates, $K_{z}$ from ADCP measurements}

We have applied the variance method to estimate $K_{z}$ from ADCP along-beam velocity measurements. According to this method, the components of Reynolds stress $-\overline{u^{\prime} w^{\prime}}$ and $-\overline{v^{\prime} w^{\prime}}$ can be calculated from the differences of the variances of the along-beam velocities of two opposing beams, as (Stacey et al., 1999a): 
In Eq. (5-6), $\tau$ is Reynolds shear stress (in pascals) with subscripts $x$ and $y$ denote along- and cross-shelf components respectively. $\theta$ is the angle each beam of the ADCP makes with vertical ( $\theta=20^{\circ}$ for the RDI ADCP used in this study), $\operatorname{var}()$ indicates the variance of a quantity, and $u$ is the along-beam velocity with subscripts indicates the beam numbers. Variance of the alongbeam velocities were calculated based on 10-min ensemble averaging periods, which has been used as the optimized averaging period in most of the studies that employed variance method (e.g., Rippeth et al., 2002;2003; Stacey et al., 1999a; 1999b).

As is mentioned earlier, the variance method has only been used in oceanographic highenergy oceanic and estuarine environments. In most of these studies, low-ping rates ( $<5$ pings per ensemble) were used (e.g., Lu and Lueck, 1999; Stacey et al., 1999b). Due to the fact that we have used it in low-energy lake environment, we have used high ping rates (55 pings per ensemble) to improved the accuracy of the along-beam velocity measurement. The standard deviation of the velocity error, $\sigma_{N}$ reduces by the square root of the number of pings, $M_{p}$ i.e., $\sigma_{N} \sim M_{p}^{-0.5}(\mathrm{RD}$ Instruments, 1996). Uncertainty estimates for the variance method have been developed by Stacey et al. (1999a), Lu and Lueck (1999), and Williams and Simpson (2004). The variance of the estimated Reynolds shear stresses using the variance method follows Eqs. (56) (Williams and Simpson, 2004):

$$
\sigma_{R}^{2}=\frac{\sigma_{N}^{4}}{M \sin ^{2} 2 \theta}
$$

where $M$ is the number of velocity values included in the estimate and $\sigma_{N}\left(=0.006 \mathrm{~ms}^{-1}\right.$ for our deployment) is the contributions to the variances of the along-beam velocity due to instrument noise. With 10-min ensemble averaging periods (i.e., $M=150$ ), the minimum detectable stress for our data can be calculated using $\tau_{\min }=\rho_{0} \sigma_{R}$, which is $\tau_{\min } \sim 0.004 \mathrm{~Pa}$. Therefore, we have removed any value of $\tau$ less than $0.004 \mathrm{~Pa}$ in our calculation, which resulted $1 \%$ of our $K_{z}$ values discarded. 
The rate of total kinetic energy production $(P)$ can be obtained from the product of Reynolds shear stress and velocity shear as (Simpson et al., 2005):

$$
P=\tau_{x} \frac{\partial u}{\partial z}+\tau_{y} \frac{\partial v}{\partial z}
$$

The vertical eddy diffusivity $\left(K_{z}\right)$ can be estimated from the total kinetic energy production and velocity shear as (Stacey et al., 1999b):

$$
K_{z}=R_{f} \frac{P}{S^{2}}
$$

In Eq. (9), the flux Richardson number, $R_{f}$ is defined in terms of the mixing efficiency $\Gamma$ as $R_{f}=\frac{\Gamma}{\Gamma+1} \leq 0.17$. The mixing efficiency $\Gamma$ defines the conversion efficiency of turbulent kinetic energy into potential energy of the system (Osborn, 1980; Shih et al., 2005). Use of $R_{f}=0.17$ (i.e., $\Gamma=0.2$ ) has been the common practice for density-stratified flows, but represents an upper bound on the efficiency of the mixing process. Hence, use of constant $R_{f}$ has been a source of vigorous discussion and it has been shown that $R_{f}$ varies strongly depending on the type of instability and the different stages of turbulence transition, i.e., initial stage of instability amplification, development of secondary instabilities and three-dimensional collapse of turbulence (see Bluteau et al., 2013; Bouffard and Boegman, 2013; Dunckley et al., 2012; Shih et al., 2005 for in-depth discussion). For example, Ivey and Imberger (1991) demonstrated that $R_{f}$ is a strong function of turbulent Froude number, $\operatorname{Fr}_{T}$ (a ratio of the largest possible turbulent scale to the active turbulent scale) and turbulent Reynolds number, $\operatorname{Re}_{T}$ (a ratio of active overturning scale to the smallest possible turbulent scale). Based on direct numerical simulations of stratified shear flows, Shih et al. (2005) observed that the assumption $\Gamma=0.2$ (i.e., $R_{f}=0.17$ ) is only valid when the turbulence intensity parameter, $I=\varepsilon / v N^{2}(\varepsilon-$ rate of dissipation of turbulent kinetic energy, $v$ - viscosity of water) is in the range between 7 and 100. Consequently, Shih et al. (2005) proposed different values of $\Gamma$ for three different regimes of turbulence classified as diffuse (for $I<7$ ), intermediate (for $7<I<100$ ), and energetic (for $I>100$ ), which are expressed with the followings:

$$
\begin{gathered}
\Gamma=0, \text { for } \mathrm{I}<7 \\
\Gamma=0.2, \text { for } 7<\mathrm{I}<100
\end{gathered}
$$


Using the estimated values of $P$ (and assuming that $P=\varepsilon$ ), we calculated $I=P / v N^{2}$ (instead of $I=\varepsilon / v N^{2}$ ) and then used Eq. (10) to calculate $\Gamma$ and $R_{f}$. Note that using $P=\varepsilon$ will not grossly affect the resulting values of $K_{z}$ as $\varepsilon=\left(1-R_{f}\right) P$ for steady, locally homogeneous stratified shear flows (Ivey and Imberger, 1991). It only affects the calculation of the range (i.e., $I<7$ and $7<I<100)$ for the cases of Eqs. (10.1) and (10.2), while it affects in calculating the actual value of $\Gamma$ for Eq. (10.3). However, for higher $I, R_{f}<<0.17$ and hence, the equal approximation of $P=\varepsilon$ is more reasonable for Eq. (10.3). Note that, recently Bouffard and Boegman (2013) extended the parameterization of Shih et al. (2005) (i.e., Eq. 10) and defined an additional buoyancycontrolled region for $1.7<I<8.5$. In an extensive comparison among different mixing efficiency models using temperature microstructure data, Dunckley et al. (2012) observed that the I-based parameterizations of Shih et al. (2005) and the extended Bouffard and Boegman (2013) produce more reliable mixing efficiency estimates compared to the $F_{T} R_{T}$ based parameterization proposed by Ivey and Imberger (1991). Based on the observation of Dunckley et al. (2012) and as our estimated resolvable $I$ is often greater than 8.5 (see result section), we have used the parameterization of Shih et al. (2005).

\section{Estimation of $K_{z}$ from high-resolution temperature measurements}

The level of turbulence can also be characterized applying the Thorpe-scale method (Thorpe, 1977) on the number and the magnitude of density inversions which can be determined from the high-resolution density profiles of the water column. This method consists of estimating vertical displacements, $d^{\prime}$ (often called a Thorpe displacement) from the rearrangement or ordering of measured density profile, which may contain inversions, into a stable monotonic profile which contains no inversions. Since density in Lake Simcoe is predominately determined by the temperature, our analysis was based on temperature inversions calculated from the thermistor chain measurement. We identified 1-m temperature inversion when the temperature difference between two vertically separated thermistors at heights $z_{1}$ and $z_{2}$ exceeds $4 \times 10^{-3}{ }^{\circ} \mathrm{C}$. This threshold is twice as high as the accuracy of the individual temperature loggers, and also represents the average of the range of values used in other studies to identify density inversions 
such as $5 \times 10^{-4}{ }^{\circ} \mathrm{C}$ in van Haren (2012) and $3 \times 10^{-3}{ }^{\circ} \mathrm{C}$ in Lorke et al. (2008). We then used a sorting algorithm to estimate Thorpe displacement $\left(d^{\prime}\right)$ from the 1-m temperature inversion.

The characteristic size of the average vertical overturn in a stratified water column is the Thorpe scale, $L_{T}$ which is the root-mean square (rms) of the displacements, $d^{\prime}$ over the vertical extent of an overturn, i.e., $L_{T}=\left\langle d^{\prime 2}\right\rangle^{\frac{1}{2}}$ (Thorpe, 1977). An estimate of the rate of dissipation of turbulent kinetic energy, $\varepsilon$ can then be made from the $L_{t}$ using the following equation:

$$
\varepsilon=\left(c L_{t}\right)^{2} N^{3}
$$

The vertical eddy diffusivity, $K_{z}$ can be estimated on the basis turbulent mass flux, using Osborn's (1980) model, which is:

$$
K_{z}=\frac{\Gamma \varepsilon}{N^{2}}=\Gamma\left(c L_{t}\right)^{2} N
$$

Note that the estimations of $\varepsilon$ and $K_{z}$ from $L_{t}$ applying Eqs. (11) and (12) are based on assuming a linear relationship between the Thorpe-scale, $L_{T}$ and Ozmidov scale, $L_{O}$ i.e., $L_{T}=c L_{O}$ ( $c$ is a constant). $L_{O}$ describes the largest possible overturning turbulent scale allowed by the buoyancy defined as $L_{O}=\sqrt{\varepsilon / N^{3}}$ (Ozmidov, 1965). A number of earlier studies (e.g., Crawford, 1986; Dillon, 1982) tested this linear relationship and obtained $c=0.8$, though few studies suggested higher values such as $c=1.06$ by Stansfield et al. (2001) and $c=1.0$ by Ferron et al. (1998). However, Dunckley et al. (2012) recently observed that this linear relationship $\left(L_{T}=c L_{O}\right)$ agrees well only in the thermocline region. In calculating $L_{t}$ from the Thorpe-displacements, $d^{\prime}$, we have only used overturns that span a distance twice of our 1-m sensor separation following the suggestion of Galbraith and Kelley (1996), who also suggested for $N$ (in Eq. 11 and 12) to be taken as the average over an area larger than the actual size of the large turbulent overturns. We calculated $N$ from the reordered, gravitationally stable density profile by applying 2-m centered differences (and backward or forward differences on the edges). In our estimation of $K_{z}$ from the Thorpe-scale method, we have used $c=0.8$ and the estimated $\Gamma$ from Eq. (10) based on $I=\varepsilon / v N^{2}$ after calculating $\varepsilon$ from Eq. (11). 
The accuracy of the estimate by Eq. (11-12) is limited by the instrument noise in the density measurement, the size of resolvable overturns, and the uncertainty associated with values of $c$ and $\Gamma$. In particular, the spacing of $1-\mathrm{m}$ thermistor sensor separation means we are undersampling smaller inversions and hence unable to observe the numerous smaller overturning events and hence will likely underestimate the estimated $K_{z}$. The Thorpe-scale method has mostly been applied to estimate intensity of turbulence from the measurements of temperature microstructure profilers (see Dunckley et al., 2012; Lorke and Wüest, 2002; Pernica et al.,2014) and Conductivity-Temperature-Depth (CTD) sensors (see Alford and Pinkel, 2000; Kitade et al., 2003; MacDonald et al., 2013) that have very high spatial resolution. It has been used for the measurements of thermistor loggers recently by van Haren et al. (2012) in the Ocean and by Cossu and Wells (2013) in lake, both with high $(\sim 10 \mathrm{~cm})$ spatial resolution focusing small portion of the water column. Only, Preusse et al. (2010) calculated $L_{T}$ deploying a thermistor chain with 1-m spatial resolution in 5-20 m depth of Lake Constance, which encouraged us to check the $K_{z}$ resolvable capability of our thermistors chain. Note that, though Preusse et al. (2010) calculated $L_{T}$ and they have not used Eq. (12) to calculate $K_{z}$ and rather, they estimated depth-averaged $K_{z}$ values from the available potential energy of unstable density fluctuation. For our thermistor chain, a minimum resolvable $K_{z}$ from the Thorpe-scale method can be approximately estimated from Eq. (12). As is discussed earlier, the value of minimum resolvable $N$ with sensor accuracy of $0.002{ }^{\circ} \mathrm{C}$ and $1-\mathrm{m}$ sensor separation is $10^{-3} \mathrm{~s}^{-1}$. Using this minimum value of resolvable $N$, constant mixing efficiency of $\Gamma=0.2$, and $L_{T}$ as the value of the sensor separation, Eq. (12) gives a minimum resolvable $K_{z}$ value as $10^{-4} \mathrm{~m}^{2} \mathrm{~s}^{-1}$. Therefore, we may not able to obtain any mixing rates that have $K_{z}<10^{-4} \mathrm{~m}^{2} \mathrm{~s}^{-1}$.

\section{Estimation of $K_{z t h}$ using heat-budget method}

A third independent measure of the turbulent diffusivity at the thermocline, $K_{z t h}$ can be made by making a budget of the rate of change of heat in the hypolimnion. The implicit assumption of the method, first proposed by Jassby and Powell (1975), is that the rate of change of heat is only due to the downward diffusion of heat from the warmer surface layer, and that the geothermal or groundwater sources of heating can be neglected. Furthermore it is assumed that the rate limiting step is the heat transport across the thermocline, so that we determine a robust time-averaged value for this diffusivity. Formulating a heat balance on the metalimnion with 
temperature, $T_{m}$ and the hypolimnion with temperature, $T_{h}$ and treating the temperature in the epilimnion, $T_{e}$ as a boundary condition, the following model results (Snodgrass, 1985):

$$
\frac{d V_{h} T_{h}}{d t}=-K_{z t h} A_{t h} \frac{\left(\bar{T}_{h}-\bar{T}_{e}\right)}{\Delta z}
$$

where $V_{h}$ is volume of the hypolimnion, $A_{t h}$ is the surface-area of thermocline, and $\Delta z$ is the thickness of temperature gradient across thermocline, and the bar indicates the average value. Assuming that the volume of the hypolimnion does not vary with time, $K_{z}$ at the thermocline can be estimated as:

$$
K_{z t h}=\bar{Z}_{h} \frac{d T_{h}}{d t} \frac{\Delta z}{\left(\bar{T}_{e}-\bar{T}_{h}\right)}
$$

Where $\bar{Z}_{h}=\frac{V_{h}}{A_{t h}}$ is the mean thickness of the hypolimnion. We have used of Eq. (14) to obtain a robust time averaged estimate of $K_{z t h}\left(K_{z}\right.$ at the thermocline) for the whole observation period, with which we can compare to a time average of the $K_{z t h}$ estimate from the variance method. The spatio-temporal variability of $K_{z}$ cannot be obtained from this method, which can be attained by applying the previous two methods.

\section{Transport of oxygen across the thermocline}

One of the goals of this study is to examine the influence of turbulent transport of DO from the epilimnion to the hypolimnion in replenishing the dissolved oxygen depletion rate at the hypolimnion, which can be expressed from the DO budget as (Bouffard et al., 2013):

$$
\frac{d \mathrm{DO}_{\mathrm{h}}}{d t}=\frac{F_{t h}}{\bar{Z}_{h}}-\frac{\mathrm{SOD}}{\bar{Z}_{h}}-\mathrm{HOD}
$$

Where $F_{t h}$ is the oxygen flux through the thermocline expressed as:

$$
F_{t h}=-K_{z t h} \frac{\left(\mathrm{DO}_{\mathrm{h}}-\mathrm{DO}_{\mathrm{e}}\right)}{\Delta z}
$$

In Eqs. (15) and (16), $K_{z t h}$ is the $K_{z}$ value at the thermocline, $\mathrm{DO}_{\mathrm{e}}$ and $\mathrm{DO}_{\mathrm{h}}$ are the $\mathrm{DO}$ concentration in the epilimnion and the hypolimnion respectively. The other two terms in the right hand side of Eq. (15) represent actual volumetric hypolimnetic oxygen depletion rate due to the oxygen consumed by the hypolimnetic water column referred to as hypolimnetic water 
oxygen demand (HOD) and by the underlying sediments referred to as sediment oxygen demand (SOD). In this study, we want to determine whether turbulence transport of DO across the thermocline is a significant portion of DO budget in the hypolimnion for our observation period.

\section{RESULTS AND OBSERVATIONS}

\section{Meteorology, stratification, and water currents}

The prevailing winds over Lake Simcoe for most of the year are westerly (Cossu and Wells, 2013), which is shown in the wind rose in Fig. 2 for our observation period based on the wind data from the Lake Simcoe meteorological buoy. The strongest wind events with speeds exceeding $10 \mathrm{~ms}^{-1}$ came from the west/northwest and were almost perpendicular to the south shore and therefore to the location of the field site in Lake Simcoe.

The main observations summarized in Fig. 3 show the response of the stratified water column to atmospheric forcing. The mean wind speed for the observational period was $4.1 \mathrm{~ms}^{-1}$ and several times the wind exceeded $8 \mathrm{~ms}^{-1}$ for extended periods (Fig. 3a). The average air temperature was $17.5^{\circ} \mathrm{C}$, and exhibits a strong diurnal cycle of cooling and warming with daytime $(8: 00$ am to $6: 00 \mathrm{pm})$ temperature being often $5{ }^{\circ} \mathrm{C}$ greater than nighttime/evening temperature (6:00 pm to 8:00 am) (Fig. 3b). Water temperature records from the top thermistor (approximately $5 \mathrm{~m}$ below the surface) indicate values constantly above $24{ }^{\circ} \mathrm{C}$ with slightly higher values at the beginning and decreasing values towards the end of the period. Diurnal variations of surface water temperatures were less than $0.2{ }^{\circ} \mathrm{C}$ suggesting negligible effect of air temperature on the surface layer for that period. Temperature records from the thermistor chain (shown in Fig. 3c) revealed that there was considerable variation in the depth of the thermocline (black line) during the observation period, with the location of the thermocline varying between depths of $10 \mathrm{~m}$ and $17.8 \mathrm{~m}$. The largest deflection of the thermocline towards the lakebed coincided with strong wind events as on DOY 224, 235 and 249. The water column was temperature-stratified at the beginning of the measurement campaign in August. The stratification grew stronger and the thermocline moved deeper until DOY 235 and after that the stratification started to weaken. Several strong thermocline excursions down to depths near the lakebed can be identified such as the significant events between DOY 222-224 and DOY 248 250. These excursion events occurred during persistent strong wind events $\left(u_{W}>5 \mathrm{~m} / \mathrm{s}\right)$. The ADCP measurements of the along-shore and cross-shelf velocity data are illustrated in Figs. $3 \mathrm{~d}$ 

order $0.1 \mathrm{~ms}^{-1}$ are seen in the upper water column, particularly after strong wind events $\left(u_{W}>5\right.$ $\mathrm{ms}^{-1}$ persistently for 12 hours), e.g. DOY 223-230, 235-238 and 240-245.

The time series of estimated shear $\left(S^{2}\right)$, buoyancy frequency $\left(N^{2}\right)$, the stability parameter $\left(S_{T}\right)$, the Lake number $\left(L_{N}\right)$, and the gradient Richardson number $\left(R i_{g}\right)$ from the measured wind speed, thermal stratification and water currents are shown in Fig. 4. The stability of the water column does not vary by significant amount in DOY 216-240 with $S_{T}$ is in the range of 750-1000 $\mathrm{Kg} \mathrm{s}^{-2}$, except the persistent wind event DOY 223-224.5 in which $S_{T}$ dropped below $500 \mathrm{Kgs}^{-2}$. During DOY 241-257, $S_{T}$ falls below $500 \mathrm{Kgs}^{-2}$ except DOY 244-248 in which $S_{T}$ increases to $750-800 \mathrm{Kgs}^{-2}$. The Lake numbers, $L_{N}$ ranges from 0.3 to 20 in the observation period, with low values $\left(L_{N}<1\right)$ corresponding to the persistent high wind events (comparing Figs. 4a and 4b). Comparing the time series of the wind speed, $u_{w}$ in Fig. $4 \mathrm{a}, S_{T}$ and $L_{N}$ in Fig. $4 \mathrm{~b}$ indicates that that the events of $L_{N}<1$ are caused by mainly increased wind forcing as $S_{T}$ has less effect in causing $L_{N}$ to dramatically change. As has been discussed earlier, $L_{N}$ varies depending on the ratio $\frac{S_{T} z_{t}}{u_{w}^{2}}$. Taking specific example of DOY 223-224 in which persistent $L_{N}<1$ occurred, $S_{T}$ reduces approximately from 1000 in the earlier period (DOY 216-220) to around 600 , while $u_{w}$ increases $4 \mathrm{~ms}^{-1}$ to $8 \mathrm{~ms}^{-1}$. Therefore, change of $S_{T}$ caused only 1.6-times decrease, while increase of $u_{w}$ caused 4-time decrease of the ratio $\frac{S_{T} z_{t}}{u_{w}^{2}}$. The mean depth of the thermocline only increased from $13 \mathrm{~m}$ in DOY 216-220 to $16 \mathrm{~m}$ in DOY 223-224.

The distribution of buoyancy frequency calculated from every 4-s temperature profile measurements are shown in Fig. 4c. The maximum value of buoyancy frequency, $N^{2}$ coincides with the thermocline (Fig. 4c), where the mean value is $5.7 \times 10^{-3} \mathrm{~s}^{-2}$. However, the value of $N^{2}$ in the thermocline was higher (mean value $\sim 7 \times 10^{-3} \mathrm{~s}^{-2}$ ) for day 216-240, which decreases afterwards (mean value $\sim 4 \times 10^{-3} \mathrm{~s}^{-2}$ for day 240-257) as overall water column stability decreases due to a gradual cooling of the surface layer (see Fig. 3b). Frequent occurrence of very low values of $N^{2}\left(>10^{-5} \mathrm{~s}^{-2}\right)$ occurred in the epilimnion, with sporadic events of low values in the hypolimnion. Inversion events (shown as white spaces in Fig. 4c) with values of $N^{2}<0$ occurred 

hypolimnion. The bottom periodic temperature inversions can be associated with the upwelling events that lead to shear driven convective instabilities (Cossu and Wells, 2013; Lorke et al., 2005). Vertical current shear is often maximum at or near the thermocline with intermittent high values of $S^{2}$ in the epilimnion and the hypolimnion (Fig. 4d). The mean value of the $S^{2}$ in the thermocline is $2.5 \times 10^{-3} \mathrm{~s}^{-2}$. In Fig. $4 \mathrm{~d}$, the distribution of the logarithm of the gradient Richardson number, $R i_{g}$ normalized by its critical values of 0.25 is shown. $R i_{g}$ values are well-above the critical value in the metalimnion, with mean value of $R i_{g}$ in this layer is 31. Approximately $10 \%$ of the time $R i_{g}$ dropped below 1.0. The epilimnion is characterized by many low values of $R i_{g}$ that are below the critical values. Among the events with $R i_{g}<1,97 \%$ of the values populated in the epilimnion and the remaining $3 \%$ is in the hypolimnion.

The Ontario Ministry of Environment (OMOE) biweekly monitoring data of temperature and DO levels at the site S15 (see Fig. 1) for a longer period (DOY 117-328, $27^{\text {th }}$ April $-24^{\text {th }}$ November) than our observational period in 2011 are plotted in Figs. 5a and 5b. Around $9^{\text {th }}$ June (DOY 160) the stratification started to form and the location of the thermocline is indicated by the solid black line. The dashed black line indicates the position of the thermocline based upon measurements made with our fast response (every $4 \mathrm{~s}$ ) thermistors in our field site. The continuous measurements of the thermocline indicate that there is considerable variability in the location of the thermocline which is not captured by the bi-weekly profile observations of OMOE. The DO can be seen to decrease beneath the thermocline after day $8^{\text {th }}$ August (DOY 220) in Fig. 5c in which we have plotted depth-averaged DO in the epilimnion and the hypolimnion. Beyond DOY 220, the DO levels drop below $7 \mathrm{mgL}^{-1}$, which is the level needed a viable cold-water fish habitat (Young et al.,2011). The decrease in DO in the epilimnetic waters is associated with increases in surface water temperatures and hence there is a lower solubility, whereas in the hypolimnion it is a result of oxygen depletion from decaying organic matter. The volumetric oxygen concentration in the hypolimnion reduces $12.1 \mathrm{mgL}^{-1}$ on sampling DOY 162 $\left(11^{\text {th }}\right.$ June $)$ to $6.3 \mathrm{mgL}^{-1}$ on sampling DOY $252\left(9^{\text {th }}\right.$ September $)$. It represents a mean hypolimnetic oxygen depletion rate of $0.065 \mathrm{mgL}^{-1} \mathrm{~d}^{-1}$, which we will use as a representative depletion rate for our observation period as DOY 252 is the last sampling day within our 
observation period. This depletion rate in 2011 is similar to the ranges observed in other years that are between 0.05 to $0.08 \mathrm{mgL}^{-1} \mathrm{~d}^{-1}$ in Lake Simcoe (see Young et al., 2011).

\section{Distribution of the intensity of internal vertical turbulent mixing in Lake Simcoe}

The distributions of estimated turbulence parameters from using the variance method on the ADCP measurements shown in Fig. 6 exhibit highly intermittent behavior both spatially and temporally. In Fig. 6b, the distribution of logarithm of turbulence intensity parameter, $I$ normalized by 100 for the observational period are plotted as a function of depth. We have chosen $I=100$ to normalize the $I$ distribution in Fig. 6b following Shih et al. (2005) who identified two different regimes namely intermediate $(I<100)$ and energetic $(I>100)$ of turbulence. The turbulence intensity parameter, $I$ is the ratio between the destabilizing effects of the turbulence and stabilizing effects of the buoyancy and the viscosity. There are relatively high values of $I$ in the epilimnion and relatively low values of $I$ in the hypolimnion and the timing of the intermittent high values of $I$ is closely correlated to low $L_{N}\left(L_{N}<1\right)$ and persistent strong wind events $\left(\mathrm{u}_{\mathrm{W}}>5 \mathrm{~m} / \mathrm{s}\right)$ shown in Fig. 6a. $I$ values are well above 100 in the epilimnion and hence, is energetic. In the metalimnion, $I$ is well below 100 for more than $80 \%$ of the observation period with mean and median values of 68 and 45 respectively. $I>100$ events occurred frequently (more than $50 \%$ of the time) in the hypolimnion. The spatial and temporal distributions of vertical turbulent eddy diffusivity, $K_{\mathrm{z}}$ expectedly exhibit similar behavior with $I$ (Fig. 6c). At the thermocline, $K_{\mathrm{z}}\left(K_{\mathrm{z}}\right.$ is on the order of $\left.10^{-6} \mathrm{~m}^{2} \mathrm{~s}^{-1}\right)$ are one order of magnitude higher than the respective molecular values of heat. However, above the thermocline they are frequently 2-3 orders of magnitudes higher, and the timing of these high mixing events is closely correlated to increases in wind speed. Sporadic events of moderately high values of $K_{z}$ can also be seen in the hypolimnion, which is likely due to up- and down-welling events as they occurred after thermocline tilting (Cossu and Wells, 2013). We could not obtain the occurrence of bottom turbulence in Figs. 6c as our ADCP measurements were limited above $2.3 \mathrm{~m}$ from the bottom. The timing of the occurrence of bottom turbulence can be seen in Fig. 6d, in which we plotted the distribution of large-amplitude ( $\geq 1-\mathrm{m})$ vertical density inversions represented by the Thorpedisplacement, $d^{\prime}$. Note that this large amplitude $d^{\prime}$ can be used as an indicator of the turbulence (see Preusse et al., 2010). Sporadic events of $d^{\prime} \geq 1$-m occurred approximately 10-12 hours after the high wind events. 
In Fig. 7, we present profiles of mean values of temperature, $S^{2}, N^{2}$ and $K_{z}$ for the full observational period. The arrow sign in each figure denotes the values at the thermocline, along with of which the preceding and the following values are in the metalimnion. The corresponding depths of the arrow signs are approximate positions, as the thermocline oscillates (see Fig. 3). The epilimnion mean temperature for the observational period is more than $20{ }^{\circ} \mathrm{C}$, while the hypolimnion mean temperature is around $10{ }^{\circ} \mathrm{C}$. The temperature gradient is expectedly highest at the metalimnion with $3{ }^{\circ} \mathrm{C} / \mathrm{m}$ (Fig. 7a). The maximum values of mean $S^{2}$ and $N^{2}$ are at the thermocline, which are more than one order of magnitude higher than those of the epilimnion and the hypolimnion (Fig. 7b). $\left\langle K_{z}\right\rangle$-profile in Fig. 7c shows that the epilimnion is characterized with high mixing, the hypolimnion and the metalimnion with low mixing.

The mean value of the $K_{z}$ at the thermocline from the variance method is on the order of $10^{-6} \mathrm{~m}^{2} \mathrm{~s}^{-1}$ (i.e. one order of magnitude higher than molecular diffusivity). We can also make an independent estimate of $K_{z}$ in the thermocline using the heat budget method, i.e., using Eq. (14) to estimate $\left\langle K_{z t h}\right\rangle$. From the analysis of our hypolimnion temperature for the observational period, we have observed that $d T / d t$ is in the range of $0.04-0.05{ }^{\circ} \mathrm{C} / \mathrm{day}$. Using $d T / d z=3{ }^{\circ} \mathrm{C} / \mathrm{m}$ (Fig. 7a), $d T / d t=0.05{ }^{\circ} \mathrm{C} /$ day, and mean hypolimnion thickness, $Z_{h}=10 \mathrm{~m}$, we obtain an approximate value of $\left\langle K_{z t h}\right\rangle$ for the whole observation period as $2 \times 10^{-6} \mathrm{~m}^{2} \mathrm{~s}^{-1}$, i.e. the same order of the magnitude of $\left\langle K_{z t h}\right\rangle$ obtained from the variance method.

Our estimated values of $K_{z}$ from the variance method show good agreement with published temperature microstructure-based $K_{z}$ estimates made by Schwalb et al. (2013) in Lake Simcoe, five days before our measurements began. Schwalb et al. (2013) collected 26 microstructure profiles or 1664 vertical segments using SCAMP (Self Contained Autonomous Profiler, Precision Measurement Engineering Inc., Vista, California, USA) on the $28^{\text {th }}$ and $29^{\text {th }}$ July of 2011 ( 5 days before of our observation start date) in 5 different stations. One of the stations was near S15, and hence very close to our field site. The environmental conditions on these two days were very similar to our observation period with mean wind speed at the day time on the $28^{\text {th }}$ July was $5.8 \mathrm{~ms}^{-1}$ (standard deviation: $1.5 \mathrm{~ms}^{-1}$ ) and on the $29^{\text {th }}$ July was $4.12 \mathrm{~ms}^{-1}$ (standard deviation: $1.4 \mathrm{~ms}^{-1}$ ), and air temperature was around $23{ }^{\circ} \mathrm{C}$. Similarly the depth and strength of the thermocline was essentially same as it was a week later when our measurement began. Using measured values of $K_{z}$, they calibrated a simplified parameterization of $K_{z}$ as a 
function of $N^{2}$ in the form of $K_{z}=\alpha\left(N^{2}\right)^{\beta}$ proposed by Gargett and Holloway, (1984) and Welander, (1968). In this expression, $\alpha$ and $\beta$ are the two constant parameters which varies depending on the level of turbulence. Schwalb et al. (2013) obtained two sets of calibrated values based on their measurements: $\alpha=3.5 \times 10^{-7}$ and $\beta=-0.53$ for the weakly-stratified region including both the epilimnion and the hypolimnion with $N^{2}<10^{-4} \mathrm{~s}^{-2}$; and $\alpha=4.3 \times 10^{-10}$ and $\beta=-1.1$ for strongly-stratified thermocline region with $N^{2}>10^{-4} \mathrm{~s}^{-2}$. The prediction of this parameterization with the calibrated values by Schwalb et al. (2013) agreed well with a plot of $K_{z}$ from the variance method as function of $N^{2}$ for the first one week of our observation period.

\section{Oxygen flux across the thermocline}

The transport of DO into the hypolimnion from the epilimnion through the thermocline is governed by vertical diffusivity at the thermocline, $K_{z t h}$, the thickness of the metalimnion, $\Delta z$ and the dissolved oxygen concentration in the epilimnion, $\mathrm{DO}_{e}$ and in the hypolimnion, $\mathrm{DO}_{h}$ (see Eq. 16). From Fig. $7 \mathrm{~d},\left\langle K_{z t h}\right\rangle$ is on the order of $10^{-6} \mathrm{~m}^{2} \mathrm{~s}^{-1}$, in agreement with independent estimates from the heat budget method. Based on the OMOE bi-weekly monitoring data shown in Fig. 5b, we first calculate an approximate value of oxygen depletion rate using the DO concentration at the lowest sampling station on sampling DOY 162 (i.e., $\mathrm{DO}_{h}=12.1 \mathrm{mgL}^{-1}$ ) and on DOY 252 (i.e., $\mathrm{DO}_{h}=6.3 \mathrm{mgL}^{-1}$ ) as $\frac{d \mathrm{DO}_{\mathrm{h}}}{d t}=-0.065 \mathrm{mgL}^{-1} \mathrm{~d}^{-1}$ or $2 \mathrm{gm} \mathrm{m}^{-3}$ month $^{-1}$. We have chosen these two days because around sampling day on the $11^{\text {th }}$ June (DOY 162) stratification started and while sampling day on the $9^{\text {th }}$ September (DOY 252) is within our observation period. Using approximate values of $\mathrm{DO}_{\mathrm{e}}\left(=8.3 \mathrm{mgL}^{-1}\right)$ and $\mathrm{DO}_{\mathrm{h}}\left(=6.6 \mathrm{mgL}^{-1}\right)$ that occurred in our observation period (from OMOE data), $K_{z t h}$ at the thermocline as $10^{-6} \mathrm{~m}^{2} \mathrm{~s}^{-1}, \Delta z=2 \mathrm{~m}$ (Fig. 7a), and $Z_{h}=10 \mathrm{~m}$, in Eq. (16) provide $F_{t h} / Z_{h} \sim+0.15 \mathrm{gm} \mathrm{m}^{-3} \mathrm{month}^{-1}$. This estimate implies that the magnitude of the turbulent DO flux is close to $10 \%$ of depleted DO in the hypolimnion caused by the SOD and the HOD, similar to the estimate in Lake Ontario (Snodgrass, 1977) and in Lake Erie (Bouffard et al., 2013). 


\section{DISCUSSION}

\section{Variability of $K_{z}$ with environmental forcing}

The internal turbulent mixing in Lake Simcoe exhibits considerable spatial variability with relatively high values of $K_{z}$ in the epilimnion and relatively low (but non-zero) values in the hypolimnion and the thermocline (Fig. 7c). This vertical variability is consistent with previous observations in dimictic lakes (see the review paper by Wüest and Lorke, 2003 and reference therein). In the epilimnion, which is nearly isothermal (see Fig. 7a), $K_{z}$ value is high on the order of $10^{-4}-10^{-3} \mathrm{~m}^{2} \mathrm{~s}^{-1}$. In the metalimnion, in contrast, the water is strongly stratified, which strongly damps any shear driven turbulence and associated mixing. Hence, the mean value of the $K_{z}$ at the thermocline is on the order of $10^{-6} \mathrm{~m}^{2} \mathrm{~s}^{-1}$ (i.e. one order of magnitude higher than molecular diffusivity). The hypolimnion, which is often calm, shows $K_{z}$ is on the order of $10^{-5} \mathrm{~m}^{2} \mathrm{~s}^{-1}$. In order to analyze the temporal variability of $K_{z}$ and its correspondence with the environmental forcing, we have plotted time series of epilimnetic hourly $K_{z}$ (averaged over the epilimnion) in Fig. 8b. Significant difference in the values of $\left\langle K_{z}\right\rangle$ for $L_{N}<1$ and $\left.L_{N}\right\rangle 1$ in the epilimnion can be seen, consistent with observations from the similar sized Lake Kinneret (Yeates and Imberger, 2003). An attempt to plot epilimnetic $K_{z}$ normalized by the $K_{m}$ as a function of $L_{N}^{-1}$ in Fig. 8d shows that the trend of the data suggests similar form of Eq. (4) with $c=1058$ and $d=1.1$, i.e.:

$$
\frac{<K_{z e p}>}{K_{m}}=\frac{1058}{L_{N}^{1.1}}
$$

where the exponent $d=1.1$ is consistent with $d=1.1$ in Yeates and Imberger (2003) and $d=1$ in Romero et al. (1998), but $c=1058$ value is much higher than these two studies who obtained $c=107$ and $c=200$. One possible reason is that their findings were for the $K_{z}$ estimates in the metalimnion, which is typically less energetic than the epilimnion. A clear trend of $K_{z}$ in the metalimnion and the hypolimnion with the $L_{N}$ has not been found and hence is not shown. However, comparing the plot of time series of the thermocline diffusivity (Fig. 8c) with the $L_{N}$ shows that for $L_{N}<<1, K_{z t h}$ at the thermocline is one order of magnitude higher than the average value of $\sim 10^{-6} \mathrm{~m}^{2} \mathrm{~s}^{-1}$ (see Fig. 7c). In these events of high $K_{z t h}$, transport of elevated flux of oxygen from the epilimnion to the hypolimnion may have occurred.

As is discussed earlier, the variability of $L_{N}$ for lake Simoce is mainly caused by the persistent wind forcing (see Fig. 6), which is again demonstrated by the Fig. 8e in the plot of $L_{N}^{-1}$ 

$\mathrm{ms}^{-1}$. A trend line with the data in Fig. 8e provides the following empirical relationship:

$$
\frac{1}{L_{N}}=1.3\left(\frac{u_{w}}{5 \mathrm{~m} \mathrm{~s}^{-1}}\right)^{2.13}
$$

From Eq. (18), $L_{N}=1$ correspond to $u_{w}=4.5 \mathrm{~ms}^{-1}$, which indicates $K_{z e p}=1.8 \times 10^{-4} \mathrm{~m}^{2} \mathrm{~s}^{-1}$ from Eq. (18). A $2.5 \mathrm{~ms}^{-1}$ increase of $u_{w}$ (i.e. $u_{w}=7 \mathrm{~ms}^{-1}$ ) reduces $L_{N}$ to 0.38 and the corresponding increase of $K_{z e p}$ to $K_{z e p}=5.2 \times 10^{-4} \mathrm{~m}^{2} \mathrm{~s}^{-1}$. Eq. (18) also suggests that $K_{z e p}$ for $L_{N}=1.0$ is almost two order of magnitude higher than that with $L_{N}=3.0$. From the above discussion based on the Fig. 8, we conclude that $L_{N}$, a bulk parameter, can characterize the epilimnetic mixing of the Lake Simcoe and elevated diapycnal mixing in the epilimnion occurs for $L_{N}<1$ which agrees well with a number of past studies (e.g., MacIntyre et al., 1999; Read et al., 2011). Therefore, Lake Number can be a useful indicator of bulk values of turbulence, especially when looking at how changes in wind and stratification may influence turbulence during the strongly stratified summer period when hypoxia may occur. However our results in Fig. 8e (expressed by Eq. 18) must be used with caution and we emphasize that they might apply only when looking at strongly stratified waters when the dominant input of energy is from the wind, rather than from destabilizing surface heat fluxes. For instance the Lake number would not be a useful predictor of diffusivity in Lake Simcoe in the fall when the water column is largely well mixed, and both wind and surface cooling provide input of energy to drive turbulence. The intensity of the mixing rates appears highly correlated with the strength and duration of the applied wind speed stress. We can set the threshold of wind speed and duration that correspond to $L_{N}<1$ for elevated mixing. Since $L_{N}$ has been calculated with 12-hour moving average of recorded hourly wind speed, a 12-hour persistent $u_{w}=5 \mathrm{~ms}^{-1}$ can be set as the threshold wind speed and duration.

The observations of intermittent higher values of stronger mixing, especially in the thermocline (Fig. 8c) contradict some of the assumptions used in previous modeling studies on Lake Simcoe. For example, in developing a phosphorus mass-balance model, Gudimov et al. (2012) assumed a fully mixed epilimnion but no turbulent mixing between the epilimnion to the hypolimnion. In contrast Nürnberg et al. (2012a; 2012b) assumed frequent exchange between the bottom and surface layers in their analysis of internal phosphorus loading in Lake Simcoe. This assumption was made as the morphometric indices (computed as the mean depth divided by the 
square root of lake area) of the lake are low which they interpreted as meaning that vertical mixing occurs more rapidly. However Fig. 8c suggest that mixing the between the bottom and the surface layers occurs in Lake Simcoe is neither frequent nor fully absent, but is mainly episodic in nature.

Based on the above analysis on our field study, the average turbulence processes for summer stratified conditions in Lake Simcoe are summarized in Fig. 9. The nearly-isothermal epilimnion shows high values of $K_{z}$ in the range of $10^{-3}-10^{-4} \mathrm{~m}^{2} \mathrm{~s}^{-1}$ depending on the strength of the wind-forcing and the stratification. $K_{z}$ in the metalimnion is of the order of $10^{-6} \mathrm{~m}^{2} \mathrm{~s}^{-1}$ and in the hypolimnion $K_{z} \sim 10^{-5} \mathrm{~m}^{2} \mathrm{~s}^{-1}$, although they both may show variability of one order of magnitude depending on the deflection of the thermocline. $K_{z}$ values in the swash zone are from the study of Cossu and Wells (2013) who investigated variability in $K_{z}$ values caused by the thermocline movements intersecting the lakebed. They have observed that $K_{z}$ varies by up to two orders of magnitude between up- and down-wellings. When the thermocline rises, estimates of turbulent diffusivity are high with $K_{z} \sim 10^{-4} \mathrm{~m}^{2} \mathrm{~s}^{-1}$, whereas during downwelling events the nearbed stratification is greatly increased and the turbulence is reduced. Sporadic mixing events at the benthic layer also occurred indicated by the frequent large-amplitude ( $\geq 1-\mathrm{m})$ vertical density inversions in Fig. 6d and the representative quantitative value (for these inversions is $K_{z} \sim 10^{-4}$ $\mathrm{m}^{2} \mathrm{~s}^{-1}$ (applying Eq. 12 with representative $N$ and $L_{T}$ for bottom 2-m). All these values of diffusivity during summer stratification are broadly consistent with those previously described in other lakes of similar size (i.e. see review of Wüest and Lorke, 2003).

\section{Characterization of internal turbulent mixing with $R i_{g}$}

In Fig. 10, we examined the correlation between the estimated $K_{z}$ from the variance method with $R i_{g}$ which exhibits the expected inverse relationship. $K_{z}$ are approximately one order of magnitude smaller for $R i_{g}>>1$ as compared to $R i_{g}<0.25$. We also compare the estimated $K_{z}$ values with the empirical parameterizations by Munk and Anderson (1948) (Eq. 2.1), by Lozovatsky et al. (2006) (Eq. 2.3), and the popular KPP parameterization (Eq. 2.2). All of these three $K_{z}$ parameterizations have originally been proposed for oceanic mixing, though that of Munk and Anderson (1948) and Lozovatsky et al. (2006) have recently been used to describe internal mixing in Lake Erie (see Loewen et al., 2007; Bouffard et al., 2013). In all of these parameterizations in Eq. (2.1-2.3), $K_{o}$ is the value of the eddy diffusivity during neutral 
conditions. The suggested value of $K_{o}$ is $K_{o}=50 \times 10^{-4} \mathrm{~m}^{2} \mathrm{~s}^{-1}$ in Large et al. (1994), $K_{o}=50 \times 10^{-4}-150 \times 10^{-4} \mathrm{~m}^{2} \mathrm{~s}^{-1}$ in Pacanowski and Philander (1981) for oceanic mixing. In Lake Erie, Loewen et al. (2007) suggested a value in the range of $10^{-3}-10^{-2} \mathrm{~m}^{2} \mathrm{~s}^{-1}$, while Bouffard et al. (2013) used a lower value of $K_{o}=2 \times 10^{-4} \mathrm{~m}^{2} \mathrm{~s}^{-1}$. The best-fit value of $K_{o}$ for our observation shown in Fig. 10 is $6 \times 10^{-4} \mathrm{~m}^{2} \mathrm{~s}^{-1}$. We have used critical value of $R i_{c r}=1$ for Eq. (2.2) and (2.3) which provided best prediction to our data. This is perhaps a result of larger sampling interval (=1-m) than the size of the instability. In such case $R i_{c r}=1$ was observed in few studies (e.g., Polzin, 1996; Van Gastel and Pelegri, 2004) although the theoretical value is 0.25. The other two best-fit parameters for the parameterization of Lozovatsky et al. (2006) are $R i_{b}=0.15$ and $p_{1}=$ $5 / 3$ consistent with the observations of Bouffard et al. (2013) for $R i_{g}$ measured with $1-\mathrm{m} \mathrm{bin}$. It can be seen that the prediction of the parameterizations of Munk and Anderson (1948) and Lozovatsky et al. (2006) are in better agreement with the data than that of the popular KPP parameterization.

\section{Environmental implications}

\section{Transport of dissolved oxygen across the thermocline}

We note that while the mean value of the $K_{z}$ at the thermocline is on the order of $10^{-6} \mathrm{~m}^{2} \mathrm{~s}^{-}$ ${ }^{1}, K_{z}$ in the metalimnion shows temporal variability and that more than $5 \%$ of our observational period showed higher values closer to $10^{-5} \mathrm{~m}^{2} \mathrm{~s}^{-1}$ (see Fig. 8c) in which case significant transport of DO may have occurred. In general these larger diffusivities are associated with stronger wind events, so that the total estimate of DO flux will be somewhat dependent on year-to-year variability in strong wind events. Similarly, $K_{z}$ in the swash zone would also act as a strong source of DO to the hypolimnion from the epilimnion, and may be a significant pathway to supply nutrients to the epilimnion from the hypolimnion.

The year-to-year variability in strong wind events could have a strong impact upon the spatio-temporal variability of turbulent mixing and turbulent transport of DO into the hypolimnion of Lake Simcoe. In Fig. 11a, we present a simple measure of the annual summer time (June-September) variability of wind speed using NARR data for 1981-2011. To analyze the inter-annual variability of wind speed, we have used NARR data because of its longer record (available from the year 1981) than that of the Lake Simcoe meteorological buoy (only available 
from the year 1999). The histograms of the wind speed follow a Weibull distribution. As the highest values of $K_{z t h}$ correspond to the periods of stronger wind forcing for Lake Simcoe, in windier summers we expect that the temporal average of $K_{z t h}$ will also be higher and hence turbulent mixing could have been responsible for a considerable flux of oxygen into the hypolimnion during those years. The variability of winds appears to be greater in the last decade (2001-2011) compared to (1981-2000). As we have demonstrated earlier, high mixing events in which significant amount of oxygen transport in the hypolimnion may have occurred correlated with persistent strong wind events i.e. wind speed more than $5 \mathrm{~ms}^{-1}$ for 12 hours that correspond to $L_{N}<1$. In Fig. 11b, we have plotted the number of occurrences of events with $u_{W}>5 \mathrm{~ms}^{-1}$ persistently for 12-hours (calculated with a 12-hr moving average of NARR data shown in Fig. 11a) in 1981-2011. It shows that number of $u_{W}>5 \mathrm{~ms}^{-1}$ (i.e., $L_{N}<1$ ) events is variable year to year. This observation, coupled with the trend of increasing variability associated with the wind speeds in Fig. 11a, suggests that at least some of the year-to-year variability in DO consumption rates (Young et al., 2011) could be due to changes of the turbulent mixing rates across the thermocline associated with increased number of wind driven mixing event. This variability in turbulent mixing rates may necessitate the incorporation of turbulent transport of DO, which has not been explicitly included in previous modeling efforts (see Gudimov et al., 2012; Snodgrass and Holubeshen, 1993; Young et al., 2011), in predictive models for hypolimnetic DO depletion in Lake Simcoe. An important conclusion is that at least some of the observed year-to-year variability in the HOD rates in Lake Simcoe may be due to variation in turbulent transport of DO across the thermocline, rather than just variations in phosphorus loading to water column or changes in the onset of summer stratification.

\section{Mixing Timescales}

The extent of turbulent mixing may also influence the photosynthesis activity in the negatively buoyant phytoplankton by inhibiting their settling out of the mixed layer (Lewis et al., 1984; Reynolds, 1984). The relative magnitudes of the vertical mixing timing scale, $T_{\operatorname{mix}}$ and the intrinsic settling time of the phytoplankton, $T_{\text {settling, }}$, govern the vertical distribution of the phytoplankton. The settling time scale of larger phytoplankton $(>2 \mu \mathrm{m})$ is of order $T_{\text {settling }}=2.5$ days (MacIntyre, 1998). The time scale of mixing is computed as $T_{\text {mix }}=L^{2} / K_{z}$ where $L$ is the thickness of a mixing zone (Loewen et al., 2007). When $T_{m i x}<T_{\text {settling, }}$, plankton can remain well 

in the epilimnion in the observation period of order $K_{z} \sim 10^{-4} \mathrm{~m}^{2} \mathrm{~s}^{-1}$ (Fig. 7d) with an average value of $L=12 \mathrm{~m}$ generates a timescale of close to 17 days. During periods of high winds (especially with $L_{N}<<1.0$, see Fig. 8a) $K_{z}=10^{-3} \mathrm{~m}^{2} \mathrm{~s}^{-1}$ in the epilimnion, we obtain $T_{\text {mix }}=40$ hours. $T_{\operatorname{mix}}$ in the epilimnion of Lake Simcoe varies from days to weeks due to the variability of $K_{z}$. Similarly, with $L=2 \mathrm{~m}$ and $K_{z} \sim 10^{-6} \mathrm{~m}^{2} \mathrm{~s}^{-1}$ in the metalimnion, $T_{m i x}$ is over 40 days, while $L=10 \mathrm{~m}$ and $K_{z} \sim 10^{-5} \mathrm{~m}^{2} \mathrm{~s}^{-1}$ in the hypolimnion, $T_{m i x}$ is more than 110 days. Hence $T_{m i x}<T_{\text {settling }}$ occurrs during $L_{N}<1.0$, so that the plankton could remain mixed in the epilimnion longer, whereas during periods with low winds where $L_{N}>1.0$ plankton may start to settle out of surface layer. The estimates of $T_{m i x}$ are consistent with the DO profile observations in the summer 2011 by Dittrich et al. (2013). Their measured DO profiles exhibited negligible vertical gradient in the epilimnion perhaps due to the low values (i.e., well mixed) of $T_{m i x}$, but steep vertical gradients in the metalimnion and the hypolimnion, where there is little mixing consistent with the high values of $T_{\text {mix }}$ combined with the high sediment oxygen demand to create strong gradient near the lakebed.

\section{Use of thermistor loggers for long-term monitoring of turbulent mixing}

The timing and magnitude of the largest $K_{z}$ values from thermistor chain show good agreement in both timing and magnitude of the same large events recorded by the ADCP (shown in Fig. 12b and d). This provides encouragement for further comprehensive study to find the best deployment configuration for long-term monitoring of $K_{z}$ in a stratified lake. In particular the timing and spatial distribution of the high values of $K_{z}$ shows good agreement between the two methods, but with the 1-m spacing we were not able to resolve the more frequent lower magnitude turbulent events. The fast-response thermistor loggers are able to capture the spatial and temporal variability of $K_{z}$ when the values are high due to strong wind events. Note that, in order to calculate $K_{z}$ (shown in Fig. 12d) from the Thorpe scale, $L_{T}$ (shown in Fig. 12c) using Eq. (12), we have deleted any $L_{T}$ less than twice of the sensor separation (i.e. $2 \mathrm{~m}$ ) following the suggestion of Galbraith and Kelley (1996). As such, most of the $K_{z}$ values that correspond to the overturns with $L_{T}<2 \mathrm{~m}$ in the hypolimnion and in the bottom 2-m seen in Fig. 12c are not resolved. In Fig. 12e, we plotted the correlation between the estimated $K_{z}$ value from the variance method and the Thorpe-scale method by spatial averaging the variance-method $K_{z}$ over 
the extent of the identified Thorpe overturn. It can be seen that the correlation is encouraging, but the Thorpe-scale method underestimates the $K_{z}$ estimated from the variance method for most of the time. This is perhaps because of poor vertical resolution in the thermistor chain that leads to underestimation of $L_{T}$ from potentially unresolvable small overturns and hence, underestimation of the $K_{z}$. Thus, for the reliable use of this technique in limnic environment, the capacity to resolve smaller mixing events needs to be improved.

As is discussed earlier (see method section), the minimum $K_{z}$ that can be resolved from 1$\mathrm{m}$ sensor separation in our thermistor chain is on the order of $10^{-4} \mathrm{~m}^{2} \mathrm{~s}^{-1}$. Hence, we could not resolve any value less than $10^{-4} \mathrm{~m}^{2} \mathrm{~s}^{-1}$ in the epilimnion or indeed any value in the thermocline where $K_{z}$ value is in the range of $10^{-6}-10^{-5} \mathrm{~m}^{2} \mathrm{~s}^{-1}$ (see Fig. 8d). The reliability of the estimate by the Thorpe-scale method on thermistor data is limited mainly by the size of resolvable overturns as the instrument noise plays a negligible role as the accuracy of the temperature (density) measurement with RBR temperature loggers is high. However, the size of resolvable overturn is constrained by the resolution limitation in our deployment (1-m vertical spacing between two immediate thermistors in the chain) and leads to underestimation of dissipation from the many potentially important small overturn that are less than $1 \mathrm{~m}$ in size.

In Fig. 13, we determine what would be an appropriate sensor separation in a thermistor chain configuration to resolve different ranges of $K_{z}$. In Fig. 13a, we have plotted the minimum resolvable $K_{z}$ with different values of sensor separation. The minimum resolvable $K_{z}$ in this figure has been calculated using Eq. (12) based on the value of minimum resolvable $N$ with sensor accuracy of $0.002{ }^{\circ} \mathrm{C}$, a constant value of $\Gamma=0.2$, and $L_{T}$ as the value of the sensor separation. By reducing the sensor separation which implies that smaller values of $L_{T}$ and $N$ can be resolved, and hence the sensitivity to lower values of $K_{z}$ improves. Fig. 13a suggests that a sensor separation of $0.5 \mathrm{~m}$ would resolve value $K_{z}$ higher than $10^{-5} \mathrm{~m}^{2} \mathrm{~s}^{-1}$ and in order to resolve $K_{z}<10^{-6} \mathrm{~m}^{2} \mathrm{~s}^{-1}$ sensor separation needs to be less than $5 \mathrm{~cm}$. Fig. 13a has been plotted for the sensor accuracy of $0.002{ }^{\circ} \mathrm{C}$ of the RBR loggers used in this study. In general, sensor separation should be smaller than the Ozmidov scale, $L_{O}$ to obtain a good estimate of $K_{z}$ (van Haren et al., 2012). In Fig. 13b, we have plotted the Ozmidov scale, $L_{O}=\sqrt{\varepsilon / N^{3}}$ as a function of the buoyancy frequency, $N^{2}$ (x-axis) and $K_{z} \mathrm{~m}^{2} \mathrm{~s}^{-1}$ (y-axis). $K_{z}$ values in this figure has been calculated from $\varepsilon$ with a constant mixing efficiency of $\Gamma=0.2$. For the strongly-stratified the 

other hand, for the weakly stratified the epilimnion region with $N^{2}>10^{-4} \mathrm{~s}^{-2}$ and $K_{z} \sim 10^{-4}-10^{-3} \mathrm{~m}^{2} \mathrm{~s}^{-}$ ${ }^{1}$ (see Fig. 7), $L_{O}>1-\mathrm{m}$, while for the hypolimnion with $N^{2}=10^{-5}-10^{-4} \mathrm{~s}^{-2}$ and $K_{z} \sim 10^{-5}-10^{-4} \mathrm{~m}^{2} \mathrm{~s}^{-1}$, $L_{O}$ is less than $0.5 \mathrm{~m}$.

Based on Figs. 12 and 13, we conclude that, if the thermistors chain can be deployed with much smaller vertical spacing, then thermistor loggers have the possibility to be able to be used for long time monitoring (whole summer duration) of internal turbulence mixing especially in the epilimnion, the hypolimnion, and the benthic layer. Thermistor loggers with less than $5 \mathrm{~cm}$ sensor separation would also resolve much of the diffusivity across the thermocline. However, configuring with such small sensor separation is probably unrealistic in the near future; the thermistor chain technique will probably be limited to measuring diffusivities of order of $10^{-5}$ $\mathrm{m}^{2} \mathrm{~s}^{-1}$ and higher, given the typical dissipation rates and stratification in lakes. However it is often these larger intermittent events that are responsible for most of the vertical mixing in lakes, so a chain of thermistor loggers could therefore be potentially very useful equipment for monitoring the presence of internal mixing in a stratified lake for long time. Because of the low power consumption, a thermistor chain could be deployed for 6 months, whereas our ADCP runs out of batteries and memory after just 1 month. Moreover, the deployment of a chain of thermistors, data processing and estimation of $K_{z}$ are much easier and the thermistors chain is about half the cost of a current meter.

\section{CONCLUSIONS}

Internal turbulent mixing in the thermally stratified summer waters of Lake Simcoe exhibited large spatial and temporal variability. Spatially, the nearly-isothermal epilimnion showed high values of vertical mixing rates, $K_{z}$ in the range of $10^{-3}-10^{-4} \mathrm{~m}^{2} \mathrm{~s}^{-1} . K_{z}$ in the metalimnion is in the order of $10^{-6} \mathrm{~m}^{2} \mathrm{~s}^{-1}$ and in the hypolimnion $K_{z} \sim 10^{-5} \mathrm{~m}^{2} \mathrm{~s}^{-1}$, and in both regions there was considerable variability in $K_{z}$ of one order of magnitude depending on how energetic where the movements of the thermocline. Sporadic mixing events at the benthic layer were also observed. The variability suggests that mixing the between the bottom and the surface layers that occurs in Lake Simcoe is neither frequent nor fully absent, but is mainly episodic in nature. The temporal variability of internal turbulent mixing has been characterized with the dimensionless Lake Number, $L_{N}$ and the gradient Richardson number, $R i_{g}$. A strong correlation 
between $K_{z}$ values with $L_{N}$ was observed in the epilimnion, where wind driven mixing provided the main input of energy during the stratified summer months. Turbulent mixing rates appear highly correlated with the strength and duration of the applied wind speed stress.

The environmental implications of the intermittent behaviors of internal turbulent mixing have been analyzed for Lake Simcoe, which has a history of hypolimnetic oxygen depletion. We estimated that replenishment by vertical turbulent transport of dissolved oxygen was $10 \%$ of the total oxygen depleted in the hypolimnion. We conclude that at least some of the observed yearto-year variability in oxygen depletion in the hypolimnion of Lake Simcoe may be due to the variation in turbulent transport of dissolved oxygen across the thermocline. A secondary goal of this study has been to demonstrate the usefulness of a temperature chain as an environmental monitoring tool in lakes where establishing the sources of oxygen depletion and replenishment in the hypolimnion is of concern for environmental management. By comparing their resolving capability with the more standard approach of using an ADCP, we demonstrated that deployment of thermistors with higher spatial resolution could be a useful method for long-time monitoring of $K_{z}$ in stratified lakes. We would recommend that researchers in future work consider deploying a thermistor chain with smaller spacing in the thermocline region and hypolimnion and higher spacing in the epilimnion, as this could resolve a significantly greater range of $K_{z}$, especially the more frequent low values. 
Alford, M., Pinkel, R., 2000. Observations of overturning in the thermocline: the context of ocean mixing. J. Phys. Oceanogr., 30, 805-832.

Bluteau, C.E., Jones, N.L., Ivey, G.N., 2013. Turbulent mixing efficiency at an energetic ocean site. J. Geophys. Res.: Oceans, 118(9), 4662-4672.

Bouffard, D., Boegman, L., 2011. Spatio-temporal dynamics of the basin scale internal waves in Lake Simcoe. Proceedings 7th Int. Symp. on Stratified Flows, Rome, Italy, Aug. 22-26 (6 pp.).

Bouffard, D., Boegman, L., Rao, Y.R., 2012. Poincaré wave-induced mixing in a large lake. Limnol. Oceanogr., 57(4), 1201-1216.

Bouffard, D., Boegman, L., 2013. A diapycnal diffusivity model for stratified environmental flows. Dyn. Atmos. Oceans, 61, 14-34.

Bouffard, D., Ackerman, J.D., Boegman, L., 2013. Factors affecting the development and dynamics of hypoxia in a large shallow stratified lake: hourly to seasonal patterns. Water Resources Research, 49, 2380-2394.

Bouffard, D., Boegman, L., Ackerman, J. D., Valipour, R., and Rao, Y.R., 2014. Near-inertial wave driven dissolved oxygen transfer through the thermocline of a large lake. J. Great Lakes Res., 40(2), 300-307.

Chen, C. T., Millero, F.J., 1977. Effect of salt content on the temperature of maximum density and on static stability in Lake Ontario. Limnol. Oceanogr., 22: 158-159. 
Coman, M.A., Wells, M.G., 2012. Temperature variability in the nearshore benthic boundary layer of Lake Opeongo is due to wind-driven upwelling events. Can. J. Fish. Aquat. Sci., 69(2), 282-296.

Cossu, R., Wells, M.G., 2013. The interaction of large amplitude internal seiches with a shallow sloping lakebed: observations of benthic turbulence in Lake Simcoe, Ontario, Canada. PloS One, 8(3), e57444.

Crawford, W.R., 1986. A comparison of length scales and decay times of turbulence in stably stratified flows. J. Phys. Oceanogr., 16(11), 1847-1854.

Dillon, T.M., 1982. Vertical overturns: A comparison of Thorpe and Ozmidov length scales. J. Geophys. Res., 87, 9601-9613.

Dittrich, M., Chesnyuk, A., Gudimov, A., McCulloch, J., Quazi, S., Young, J., Winter, J., Stainsby, E., Arhonditsis, G., 2013. Phosphorus retention in a mesotrophic lake under transient loading conditions: insights from a sediment phosphorus binding form study. Water Res., 47, 1433-1447.

Dunckley, J.F., Koseff, J.R., Steinbuck, J.V., Monismith, S.G., Genin, A., 2012. Comparison of mixing efficiency and vertical diffusivity models from temperature microstructure. J. Geophys. Res.: Oceans, 117(C10), C10008.

Eimers, M.C., Winter, J.G., Scheider, W.A., Watmough, S.A., Nicholls, K H., 2005. Recent Changes and patterns in the water chemistry of Lake Simcoe. J. Great Lakes Res., 31, 322 332.

Ferron, B., Mercier, H., Speer, K., Gargett, A., Polzin, K., 1998. Mixing in the Romanche Fracture Zone. J. Phys. Oceanogr., 28, 1929-1945.

Galbraith, P.S., Kelley, D.E., 1996. Identifying overturns in CTD profiles. J. Atmos. Ocean. Tech., 13(3), 688-702.

Gargett, A.E., Holloway, G., 1984. Dissipation and diffusion by internal wave breaking. J. Marine Res., 42(1), 15-27.

Gudimov, A., O’Connor, E., Dittrich, M., Jarjanazi, H., Palmer, M.E., Stainsby, E., Winter, J.G., Young, J.D., Arhonditsis, G.B., 2012. Continuous bayesian network for studying the causal 
links between phosphorus loading and plankton patterns in Lake Simcoe, Ontario, Canada. Environ. Sci. Tech., 46(13), 7283-7292.

Idso, S.B., 1973. On the concept of lake stability. Limnol. Oceanogr., 18, 681-683.

Imberger, J., Patterson, J.C., 1990. Physical limnology. in: Hutchinson, J.W., Wu, T.Y. (Eds.), Advances in Applied Mechanics, Academic Press Inc., London, pp. 303-475.

Ivey, G.N., Imberger, J., 1991. On the nature of turbulence in a stratified fluid. Part I: The energetics of mixing. J. Phys. Oceanogr., 21(5), 650-658.

Jassby, A., Powell, T., 1975. Vertical patterns of eddy diffusion during stratification in Castle Lake. Limnol. Oceanogr., 20, 530-543.

Kitade, Y., Matsuyama, M., Yoshida, J., 2003. Distribution of overturn induced by internal tides and Thorpe scale in Uchiura Bay. J. Phys. Oceanogr., 59(6), 845-850.

Kundu, P.K., Beardsley, R.C., 1991. Evidence of a critical Richardson number in moored measurements during the upwelling season off northern California. J. Geophys. Res.: Oceans, 96(C3), 4855-4868.

Large, W.G., McWilliams, J.C., Doney, S.C., 1994. Oceanic vertical mixing: a review and a model with a nonlocal boundary layer parameterization. Rev. Geophys., 32(4), 363-403.

Lewis, M., Horne, E.P., Cullen, J.J., Oakey N., Platt, T., 1984. Turbulent motions may control phytoplankton photosynthesis in the upper ocean. Nature, 311, 49-50.

Loewen, M.R., Ackerman, J.D., Hamblin, P.F., 2007. Environmental implications of stratification and turbulent mixing in a shallow lake basin. Can. J. Fish. Aquat. Sci., 64(1), 43-57.

Lohrmann, A., Hackett, B., Roed, L.P., 1990. High resolution measurements of turbulence, velocity and stress using a pulse-to-pulse coherent sonar. J. Atmos. Ocean. Tech., 7(1), 1937.

Lorke, A., Umlauf, L., Mohrholz, V., 2008. Stratification and mixing on sloping boundaries. Geophys. Res. Lett., 35(14).

Lorke, A., Peeters, F., Wüest, A., 2005. Shear-induced convective mixing in bottom boundary layers on slopes. Limnol. Oceanogr., 50(5), 1612. 
Lorke, A., Wüest, A., 2002. Probability density of displacement and overturning length scales under diverse stratification J. Geophys. Res., 107(C12), 3214.

Lorke, A., Wüest, A., 2005. Application of coherent ADCP for turbulence measurements in the bottom boundary layer. J. Atmos. Ocean. Tech., 22(11), 1821-1828.

Lozovatsky, I.D., Roget, E., Fernando, H.J.S., Figueroa, M., Shapovalov, S., 2006. Sheared turbulence in a weakly stratified upper ocean. Deep Sea Res. P. I: Ocean. Res. Pap., 53(2), 387-407.

Lu, Y., Lueck, R.G., 1999. Using a broadband ADCP in a tidal channel. Part II: Turbulence. J. Atmos. Ocean. Tech., 16(11), 1568-1579.

MacIntyre, S., 1998. Turbulent mixing and resource supply to Phytoplankton. in: Imberger, J. (Ed.), Physical Processes in Lakes and Oceans, American Geophysical Union, Washington, DC, pp. 561-590.

MacIntyre, S., Flynn, K.M., Jellison, R., Romero, J.R., 1999. Boundary mixing and nutrient fluxes in Mono Lake, California. Limnol. Oceanogr., 44(3), 512-529.

MacIntyre, S., Fram, J.P., Kushner, P.J., Bettez, N.D., O’Brien, W.J., Hobbie, J.E., Klings, G.W., 2009. Climate-related variations in mixing dynamics in an Alaskan arctic lake. Limnol. Oceanogr., 54(6, p. 2), 2401-2417.

Mesinger, F., DiMego, G., Kalnay, E., Mitchell, K., Shafran, P.C., Ebisuzaki, W, et al., 2006. North American regional reanalysis. Bull. American Meteorol. Soc., 87(3), 343-360.

Miles, J.W., 1961. On the stability of heterogeneous shear flows. J. Fluid Mech.. 10, 497-508.

Munk, W.H., Anderson, E.R., 1948. Notes on the theory of the thermocline. J. Mar. Res., 3, 276295.

Nürnberg, G.K., LaZerte, B.D., Loh, P.S., Molot, L.A., 2013a. Quantification of internal phosphorus load in large, partially polymictic and mesotrophic Lake Simcoe, Ontario. J. Great Lakes Res., 39, 271-279.

Nürnberg, G.K., Molot, L.A., O'Connor, E., Jarjanazi, H., Winter, J., Young, J., 2013b. Evidence for internal phosphorus loading, hypoxia and effects on phytoplankton in partially polymictic Lake Simcoe, Ontario. J. Great Lakes Res., 39, 259-270. 
Osborn, T.R., 1980. Estimates of the local rate of vertical diffusion from dissipation measurements. J. Phys. Oceanogr., 10(1), 83-89.

Ozmidov, R.V., 1965. On the turbulent exchange in a stably stratified ocean. Atmos. Ocean. Phys., 8, 853-860.

Patterson, J.C., Hamblin, P.F., Imberger, J., 1984. Classification and dynamic simulation of the vertical density structure of lakes. Limnol. Oceanogr, 29(4), 845-86.

Pacanowski, R.C., Philander, S.G.H., 1981. Parameterization of vertical mixing in numerical models of tropical oceans. J. Phys. Oceanogr., 11(11), 1443-1451.

Pernica, P., Wells, M.G., MacIntyre, S., 2014. Persistent weak thermal stratification inhibits mixing in the epilimnion of north-temperate Lake Opeongo, Canada. Aquat. Sci, 1-15. DOI: 10.1007/s00027-013-0328-1.

Polzin, K., 1996. Statistics of the Richardson number: Mixing models and fine structure. $J$. Phys. oceanogr., 26(8), 1409-1425.

Preusse, M., Peeters, F., Lorke, A., 2010. Internal waves and the generation of turbulence in the thermocline of a large lake. Limnol. Oceanogr., 55(6), 2353-2365.

Rao, Y.R., Hawley, N., Charlton, M.N., Schertzer, W.M., 2008. Physical processes and hypoxia in the central basin of Lake Erie. Limnol. Oceanogr., 53(5), 2007.

RD Instruments, 1996. Principles of operation a practical primer, Available from RDInstruments.com.

Read, J.S., Hamilton, D.P., Jones, I.D., Muraoka, K., Winslow, L.A., Kroiss, R., Wu, C.H., Gaiser, E., 2011. Derivation of lake mixing and stratification indices from high-resolution lake buoy data. Environ. Modell. Softw., 26(11), 1325-1336.

Reynolds, C.S., 1984. The ecology of freshwater phytoplankton. Cambridge University Press.

Rippeth, T.P., Simpson, J.H., Williams, E., Inall, M.E., 2003. Measurement of the rates of production and dissipation of turbulent kinetic energy in an energetic tidal flow: Red Wharf Bay revisited. J. Phys. Oceanogr., 33(9), 1889-1901.

Rippeth, T.P., Williams, E., Simpson, J.H., 2002. Reynolds stress and turbulent energy production in a tidal channel. J. Phys. Oceanogr., 32(4), 1242-1251. 
Robertson, D.M., Imberger, J., 1994. Lake number, a quantitative indicator of mixing used to estimate changes in dissolved oxygen. Intern. Rev. Hydrobio. Hydrogr., 79(2), 159-176.

Romero, J.R., Jellison, R., Melack, J.M., 1998. Stratification, vertical mixing, and upward ammonium flux in hypersaline Mono Lake, California. Arch. Hydrobio., 142(3), 283-315.

Schwalb, A., Bouffard, D., Ozersky, T., Boegman, L., Smith, R.E.H., 2013. Impacts of hydrodynamics and benthic communities on phytoplankton distributions in a large, dreissenid-colonized lake (Lake Simcoe, Ontario, Canada). Inland Waters, 3(2), 269-284.

Shih, L.H., Koseff, J.R., Ivey, G.N., Ferziger, J.H., 2005. Parameterization of turbulent fluxes and scales using homogeneous sheared stably stratified turbulence simulations. J. Fluid Mech., 525, 193-214.

Simpson, J.H., Williams, E., Brasseur, L.H., Brubaker, J.M., 2005. The impact of tidal straining on the cycle of turbulence in a partially stratified estuary. Cont. Shelf Res., 25(1), 51-64.

Snodgrass, W.J., 1977. Relationship of vertical transport across the thermocline to oxygen and phosphorus regimes: Lake Ontario as a prototype. in: Gibbs, R.J., Shaw, R.P. (Eds.), Transport Processes in Lakes and Oceans, Springer US, pp. 179-202.

Snodgrass, W.J., 1985. Lake Ontario oxygen model. 2. Errors associated with estimating transport across the thermocline. Environ. Sci. Tech., 19, 180-185.

Snodgrass, W.J., Holubeshen, J., 1993. Hypolimnetic oxygen dynamics in Lake Simcoe, part 3 : model confirmation and prediction of the effects of management. LSEMS Tech. Rep. Imp. B16.

Stacey, M.T., Monismith, S.G., Burau, J.R., 1999a. Measurements of Reynolds stress profiles in unstratified tidal flow. J. Geophys. Res., 104(C5), 10933-10.

Stacey, M.T., Monismith, S.G., Burau, J.R., 1999b. Observations of turbulence in a partially stratified estuary. J. Phys. Oceanogr., 29(8), 1950-1970.

Stainsby, E.A., Winter, J.G., Jarjanazi, H., Paterson, A.M., Evans, D.O., Young, J.D., 2011. Changes in the thermal stability of Lake Simcoe from 1980 to 2008. J. Great Lakes Res., 37, $55-62$. 
Stansfield, K., Garrett, C., Dewey, R., 2001. The probability distribution of the Thorpe displacement within overturns in Juan de Fuca Strait. J. Phys. Oceanogr., 31(12), 3421-3434.

Thorpe, S.A., 1977. Turbulence and mixing in a Scottish loch. Philos. Trans. R. Soc. London Ser. A., 286, 125-181.

Van Gastel, P., Pelegrí, J.L., 2004. Estimates of gradient Richardson numbers from vertically smoothed data in the Gulf Stream region. Sci. Mar., 68(4), 459-482.

van Haren, H., 2012. The ocean's internal motion: A short overview of NIOZ thermistor string observations. J. Sea Res., 74, 8-15.

van Haren, H., Gostiaux, L., Laan, M., Van Haren, M., Van Haren, E., Gerringa, L.J., 2012. Internal wave turbulence near a Texel beach. PloS One, 7(3), e32535.

Welander, P., 1968. Theoretical forms for the vertical exchange coefficients in a stratified fluid with application to lakes and seas. Acta Reg. Soc. Sci. Ltt. Gothob. Geophys., 1, 1-26.

Wiles, P.J., Rippeth, T.P., Simpson, J.H., Hendricks, P.J., 2006. A novel technique for measuring the rate of turbulent dissipation in the marine environment. Geophys. Res. Lett., 33(21).

Williams, E., Simpson, J.H., 2004. Uncertainties in estimates of Reynolds stress and TKE production rate using the ADCP variance method. J. Atmos. Ocean. Tech., 21(2), 347-357.

Winter, J.G., Eimers, M.C., Dillon, P.J., Scott, L.D., Scheider, W.A., Willox, C.C., 2007. Phosphorus inputs to Lake Simcoe from 1990 to 2003: declines in tributary loads and observations on lake water quality. J. Great Lakes Res., 33(2), 381-396.

Wüest, A., Lorke, A., 2003. Small-scale hydrodynamics in lakes. Annu. Rev. Fluid Mech., 35(1), 373-412.

Yeates, P.S., Imberger, J., 2003. Pseudo two-dimensional simulations of internal and boundary fluxes in stratified lakes and reservoirs. Int. J. River Basin Man., 1(4), 297-319.

Young, J.D., Winter, J.G., Molot, L., 2011. A re-evaluation of the empirical relationships connecting dissolved oxygen and phosphorus loading after dreissenid mussel invasion in Lake Simcoe. J. Great Lakes Res., 37, 7-14. 


\section{TABLE CAPTION}

Table 1. Details of all the measured data used in this study.

7

8 


\section{FIGURE CAPTIONS}

Fig. 1. Field experiment location and bathymetry of Lake Simcoe, Ontario (Canada). Thermistor chain and an acoustic Doppler current profiler (ADCP) were located at the Field Site indicated by circle. Also shown are the location of the Lake Simcoe meteorological buoy indicated by diamond and the long term OMOE monitoring site S15 indicated by a square. The arrow represents dominant wind direction.

Fig. 2. Wind rose based on the wind record by the buoy for the observation period DOY 216 257 (August, 4 - September, 15) in 2011. Direction indicated is that from which wind is blowing. Concentric rings (2, 4, 6 and 8) indicates percentage of time wind is from that particular direction; colors within a wedge represent the relative proportion of time the winds from that direction are of a certain magnitude.

Fig. 3. Time series of (a) vector plot of wind vector, $u_{w} \mathrm{~ms}^{-1}$ (hourly record) (b) air temperature, $T_{a}{ }^{\circ} \mathrm{C}$ (hourly record, blue line) and water temperature $5 \mathrm{~m}$ below the surface, $T_{s w}{ }^{\circ} \mathrm{C}$ (4-s record, black line), (c) water temperature, $T^{\circ} \mathrm{C}$ (4-s record), (d) ADCP velocities east, $U \mathrm{~ms}^{-1}$ (10-min average), and (e) ADCP velocities north, $V \mathrm{~ms}^{-1}$ (10-min average) for the full observational period. Position of the thermocline is marked in black in (c)-(d).

Fig. 4. Time series of (a) wind speed, $u_{w} \mathrm{~ms}^{-1}$ [hourly record (blue line) overlain by the 12-h moving average of the wind speed (black line)] with dotted black line indicates $u_{w}=5 \mathrm{~ms}^{-1}$, (b) inverse Lake Number, $1 / L_{N}$ (hourly value, black line) and Schmidt stability, $S_{T} \mathrm{kgs}^{-2}$ (hourly value, blue line) with dotted black line indicates $L_{N}=1.0$ (c) logarithm of buoyancy frequency, $\log _{10} N^{2} \mathrm{~s}^{-2}$ (4-s value), (d) logarithm of current shear, $\log _{10} S^{2} \mathrm{~s}^{-2}$ (10-min average), and (e) logarithm of gradient Richardson number normalized by the critical value of $0.25, \log _{10}$ $\left(R i_{g} / 0.25\right)$ for the full observational period. Position of thermocline was marked in white in (d) and (e). White spaces in (c) denote the negative values of $N^{2}$ that represent inversion.

Fig. 5. Time series of (a) water temperature, $T^{\circ} \mathrm{C}$ (bi-weekly value), and (b) the distribution of dissolved oxygen, DO $\mathrm{mgL}^{-1}$ (bi-weekly value) in the water column at the $\mathrm{S} 15$ site both measured by the Ontario Ministry of Environment for extended period (April 27 - November 24) of 2011. (c) Depth-averaged epilimnetic and hypolimentic DO with time, based on Fig. (b). The calculated position of thermocline is shown based on the bi-weekly measurements (black line) and our high-resolution (every 4-s) measurements for the observational period (white line). 
Fig. 6. Time series of (a) inverse Lake Number, $1 / L_{N}$ (hourly value, black line) and wind speed, $u_{w} \mathrm{~ms}^{-1}$ (12-h moving average, blue line) with dotted black line indicates $L_{N}=1.0$, (b) logarithm of turbulence intensity parameter, I normalized by 100, (c) logarithm of turbulent eddy diffusivity, $\log _{10} K_{z} \mathrm{~m}^{2} \mathrm{~s}^{-1}$ estimated from ADCP measurement, and (d) inversion length-scale, $d^{\prime} \mathrm{m}$ calculated from the temperature profile measurements by the thermistor loggers for the full observational period. Position of thermocline has been marked in black in (b)-(d). White-spaces in (b) and (c) represents unresolved $K_{z}$ by the variance method when $\tau<\tau_{\min }=0.004 \mathrm{~Pa}$.

Fig. 7. Profiles of mean (a) temperature, $\langle T\rangle{ }^{\circ} \mathrm{C}$, (b) buoyancy frequency, $\left\langle N^{2}\right\rangle \mathrm{s}^{-2}$ and current shear, $\left\langle S^{2}\right\rangle \mathrm{s}^{-2}$, and (c) vertical eddy diffusivity, $\left\langle K_{z}\right\rangle \mathrm{m}^{2} \mathrm{~s}^{-1}$ for the observational periods. Values at the thermocline are shown by an arrow in each figure. Error bars represent standard deviation.

Fig. 8. (a) Time series of inverse Lake Number, $1 / L_{N}$ (hourly value, black line) with black line represents $L_{N}=1.0$, (b) time series of the epilimnetic vertical eddy diffusivity, $\left\langle K_{z e p}\right\rangle \mathrm{m}^{2} \mathrm{~s}^{-1}$ (hourly value averaged over the epilimnion), (c) time series of the thermocline vertical eddy diffusivity, $\left\langle K_{z t h}\right\rangle \mathrm{m}^{2} \mathrm{~s}^{-1}$, (d) Epilimnetic eddy diffusivity $\left\langle K_{z e p}\right\rangle \mathrm{m}^{2} \mathrm{~s}^{-1}$ (hourly $K_{z}$ values averaged over the epilimnion) normalized by the molecular diffusivity of heat, $K_{m}\left(=1.4 \times 10^{-7}\right.$ $\mathrm{m}^{2} \mathrm{~s}^{-1}$ ) as a function of $1 / L_{N}$, and (e) $1 / L_{N}$ as a function of wind speed, $u_{w} \mathrm{~ms}^{-1}$ (12-h moving average) normalized by a threshold windspeed, $u_{w t h}=5 \mathrm{~ms}^{-1}$.

Fig. 9. Summary of internal turbulent mixing processes in Lake Simcoe with typical quantitative values of $K_{z}$ for periods of strong stratification in the summertime.

Fig. 10. Comparison of mean vertical eddy diffusivity, $\left\langle K_{z}\right\rangle$ for our field study using the variance method on ADCP measurements with the predictions of empirical parameterizations of $K_{z}$ as a function of gradient Richardson number, $R i_{g}$. Data have been averaged over similar $R i_{g}$.

Fig. 11. Annual summer (June-September) time variability of (a) the distribution of wind speed $\left(u_{W} \mathrm{~m} / \mathrm{s}\right)$ and (b) number of occurrence of events with $u_{W}>5 \mathrm{~ms}^{-1}$ persistently for 12-hours (calculated with a 12-hr moving average of the data shown in Fig. 11a) in percentage observed for the year 1981-2010 based on the three-hourly NARR data. Fig. 12. Time-series of (a) wind speed, $u_{w} \mathrm{~ms}^{-1}$ (12-hr moving average), (b) logarithm of eddy diffusivity, $\log _{10} K_{z} \mathrm{~m}^{2} \mathrm{~s}^{-1}$ using the variance method on ADCP measurement of currents, (c) the Thorpe-scale, $L_{T} \mathrm{~m}$ (d) logarithm of eddy diffusivity, $\log _{10} K_{z} \mathrm{~m}^{2} \mathrm{~s}^{-1}$ using the Thorpe-scale method on the thermistors' temperature 
measurement, and (e) comparison of $K_{z}$ estimated between the variance and the Thorpe-scale method (solid blue line denotes one-to-one correspondence). Fig. 12e has been plotted by spatial averaging $K_{z}$ from the variance-method over the extent of the resolved $K_{z}$ by the Thorpe-scale method. A background value of $K_{z}=1.4 \times 10^{-7} \mathrm{~m}^{2} \mathrm{~s}^{-1}$ has been added in (c) where no inversions were found. Position of the thermocline has been marked with black line in (b) and (c), and with white line in (c).

Fig. 13. (a) Variation of minimum resolvable vertical turbulent eddy diffusivity, $K_{z} \mathrm{~m}^{2} \mathrm{~s}^{-1}$ with sensor separation $[\mathrm{m}]$ with sensor accuracy of $0.002{ }^{\circ} \mathrm{C}$, and (b) Ozmidov scale, $L_{O}[\mathrm{~m}]$ as a function of the buoyancy frequency, $N^{2}$ (x-axis) and $K_{z} \mathrm{~m}^{2} \mathrm{~s}^{-1}$ (y-axis). $K_{z}$ values in this figure has been calculated assuming constant mixing efficiency, $\Gamma=0.2$. 
Table 1. Details of all the measured data used in this study

\begin{tabular}{|c|c|c|c|}
\hline Measured Data & $\begin{array}{l}\text { Temporal and Spatial } \\
\text { Resolution }\end{array}$ & Instruments/ Source & Length of records \\
\hline $\begin{array}{l}\text { Wind speed and } \\
\text { direction }\end{array}$ & Hourly & $\begin{array}{l}\text { Lake Simcoe } \\
\text { meteorological Buoy }\end{array}$ & $\begin{array}{l}\text { Aug. 04-Sep. 15, } \\
2011\end{array}$ \\
\hline Wind speed & 3-hourly & NARR & $\begin{array}{c}\text { June-Sep., 1981- } \\
2011\end{array}$ \\
\hline Air temperature & Hourly & $\begin{array}{l}\text { Lake Simcoe } \\
\text { meteorological buoy }\end{array}$ & $\begin{array}{l}\text { Aug. 04-Sep. 15, } \\
2011\end{array}$ \\
\hline $\begin{array}{c}\text { Water } \\
\text { temperature }\end{array}$ & $\begin{array}{l}4 \mathrm{~s}, 1-\mathrm{m} \text { vertical spacing } \\
\text { (depth: } 4.65 \mathrm{~m}-19.65 \mathrm{~m} \text { ) }\end{array}$ & TR-1060 (RBR) & $\begin{array}{l}\text { Aug. 04-Sep. 15, } \\
2011\end{array}$ \\
\hline $\begin{array}{c}\text { Water } \\
\text { temperature }\end{array}$ & $\begin{array}{c}\text { Biweekly, 1-m vertical spacing } \\
\text { (depth: } 0.1 \mathrm{~m}-20 \mathrm{~m} \text { ) }\end{array}$ & YSI probe & $\begin{array}{c}\text { April } 27-\text { Nov. 24, } \\
2011\end{array}$ \\
\hline Water current & $\begin{array}{l}4 \mathrm{~s}, 1-\mathrm{m} \text { vertical spacing } \\
\text { (depth: } 4.47 \mathrm{~m}-17.47 \mathrm{~m})\end{array}$ & $\begin{array}{l}\text { 600-kHz 4-beam } \\
\text { ADCP (RDI) }\end{array}$ & $\begin{array}{c}\text { Aug. } 04 \text { - Sep. 15, } \\
2011\end{array}$ \\
\hline $\begin{array}{l}\text { Dissolved } \\
\text { oxygen }\end{array}$ & $\begin{array}{l}\text { Biweekly, 1-m vertical spacing } \\
\text { (depth: } 0.1 \mathrm{~m}-20 \mathrm{~m} \text { ) }\end{array}$ & YSI probe & $\begin{array}{l}\text { April } 27-\text { Nov. } 24 \\
2011\end{array}$ \\
\hline
\end{tabular}




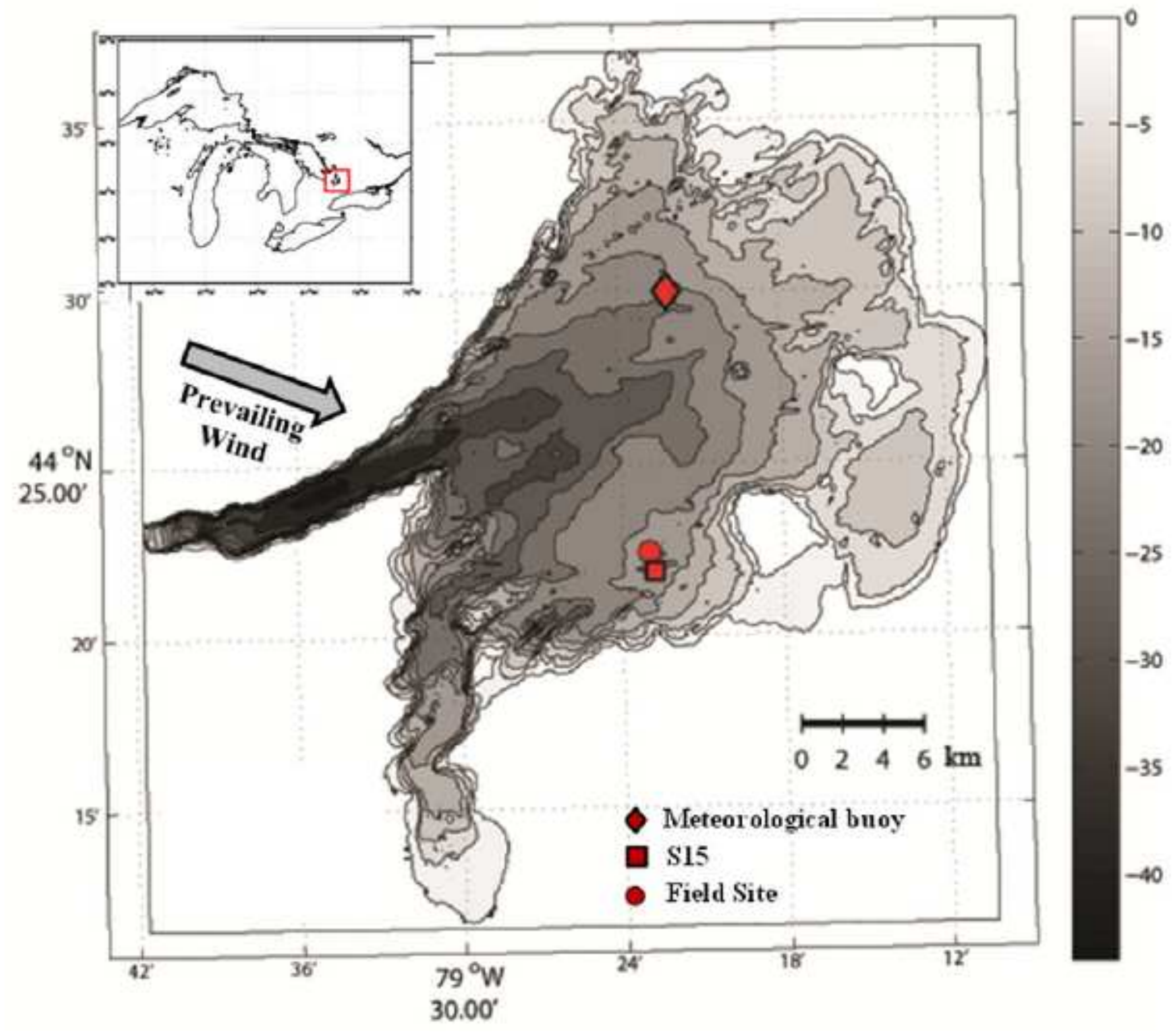




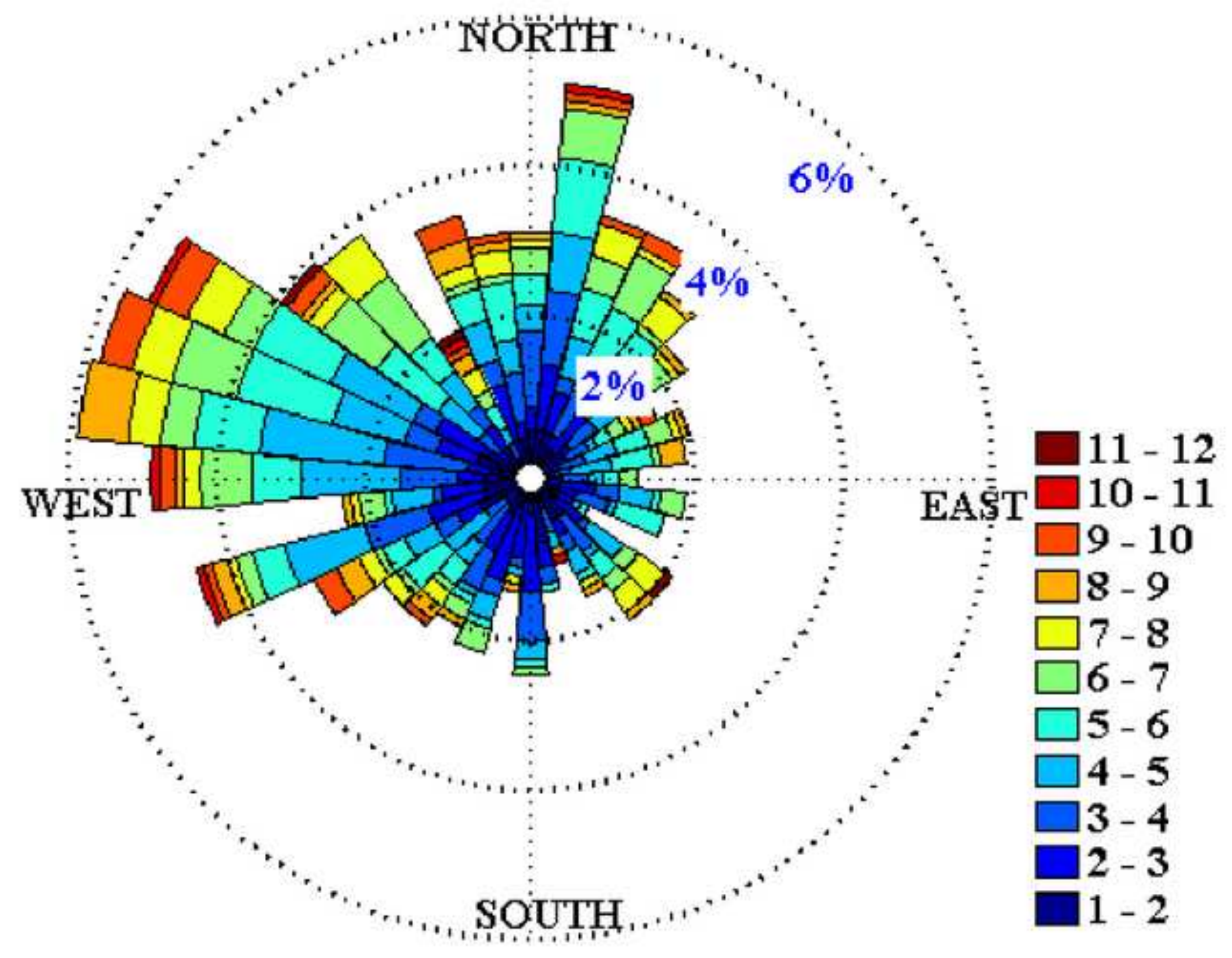


a) $=5{ }_{-5}^{5}$

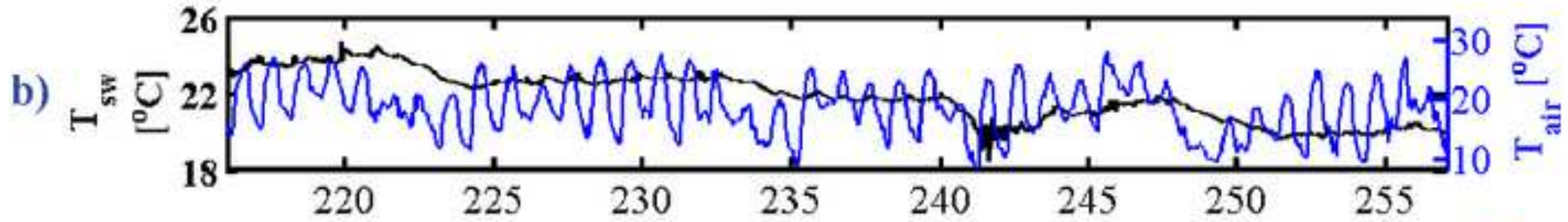

c) $\begin{gathered}5 \\ 0\end{gathered}$

d)

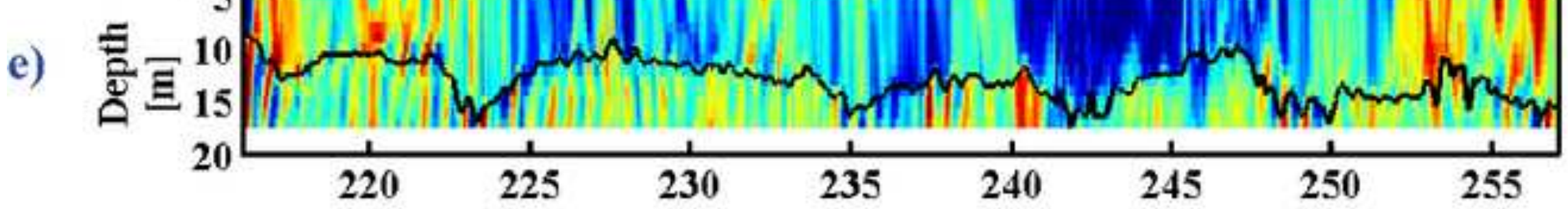
Day of Year

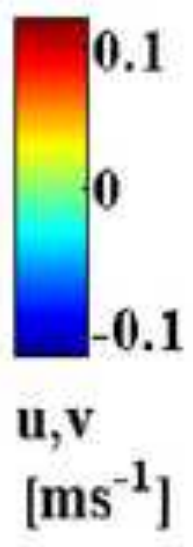




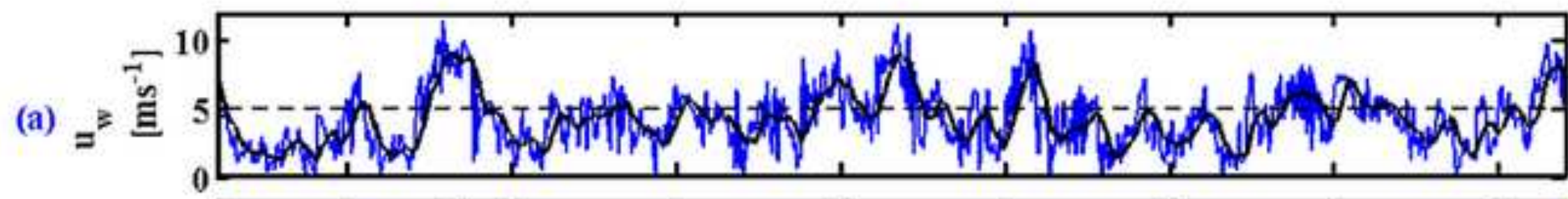

(b)

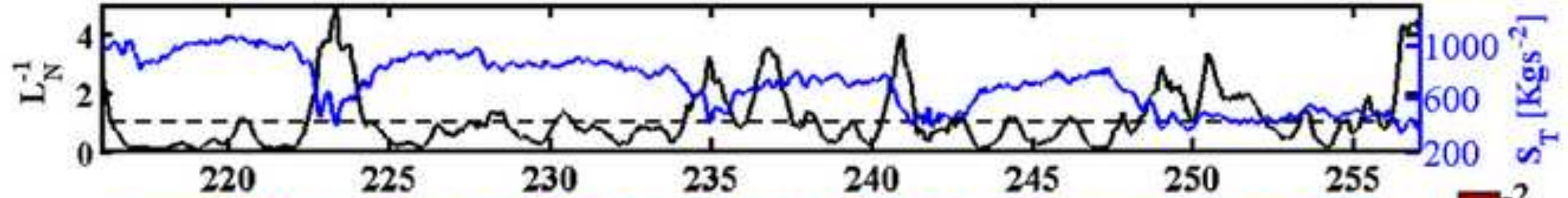

(c) $\mathrm{C}_{0}{ }_{20}^{10}$

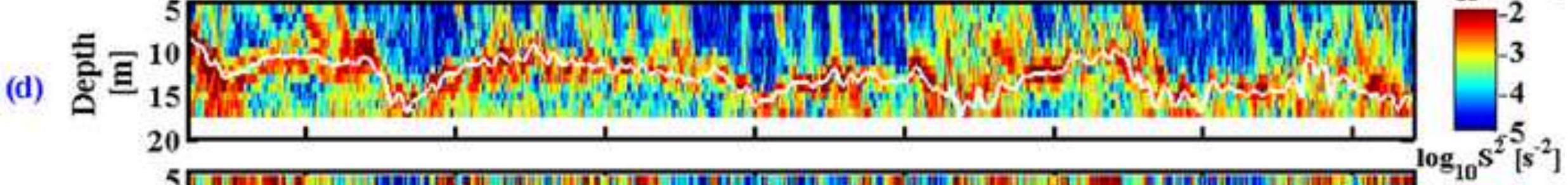

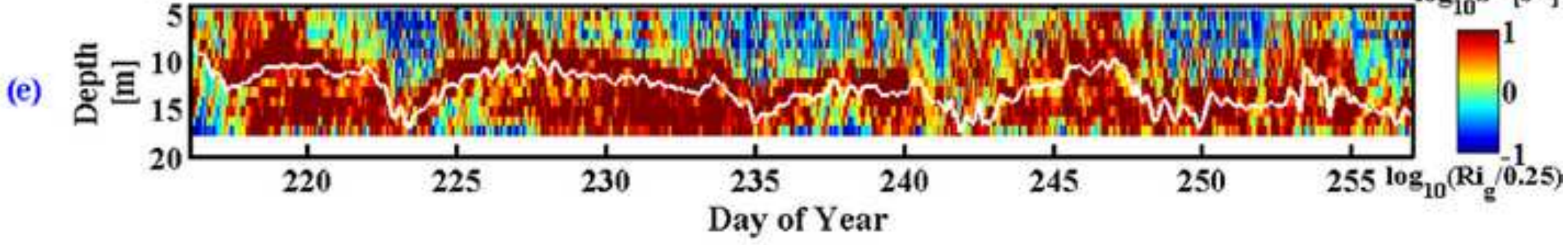


a)
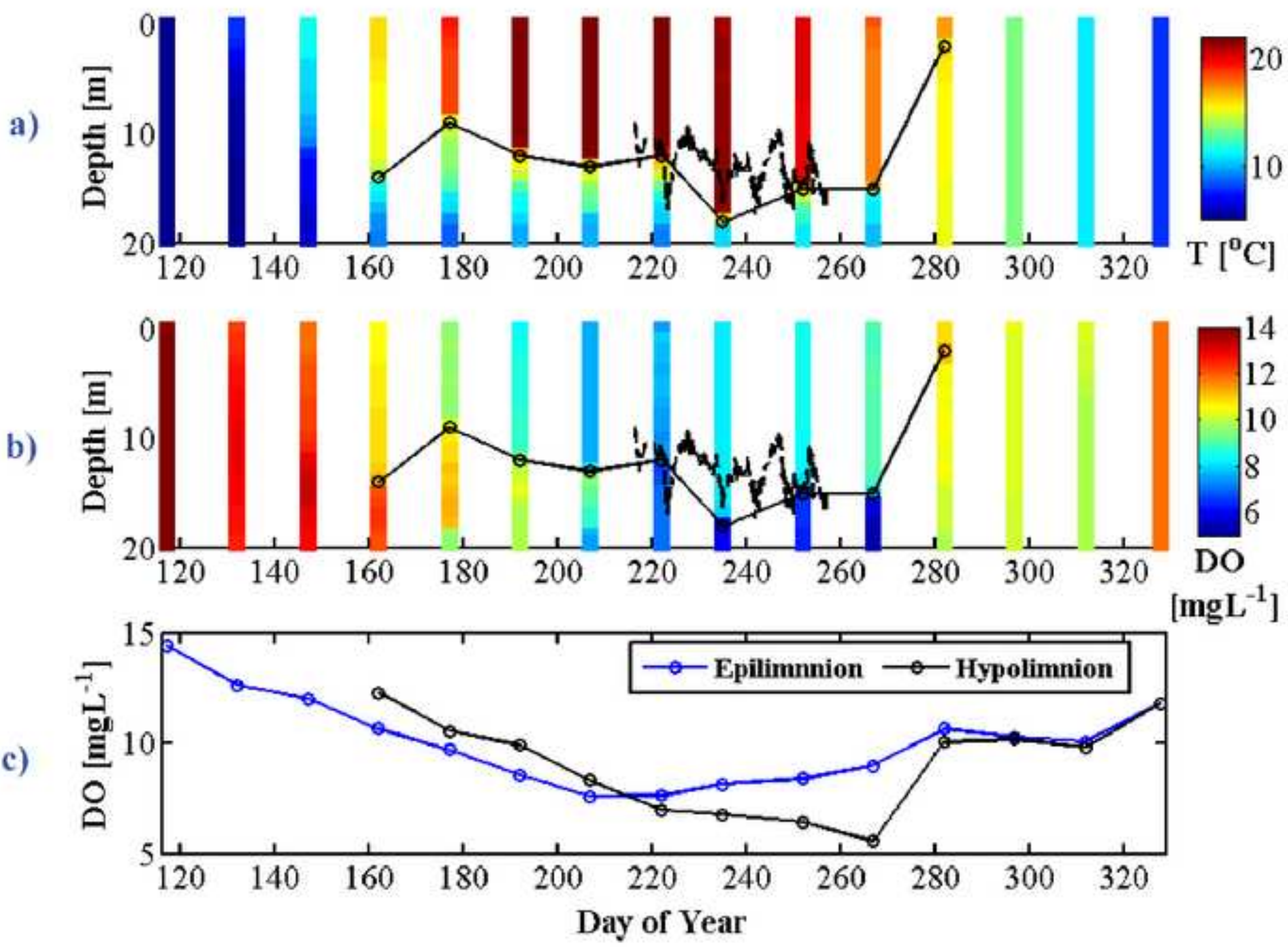
(9)

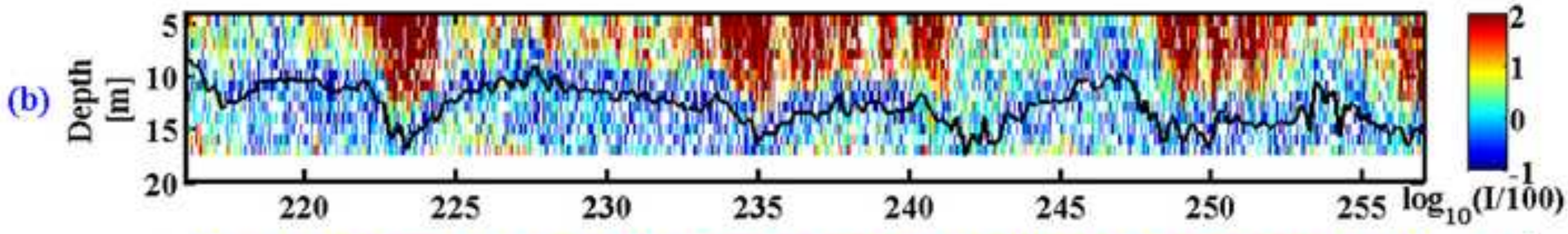

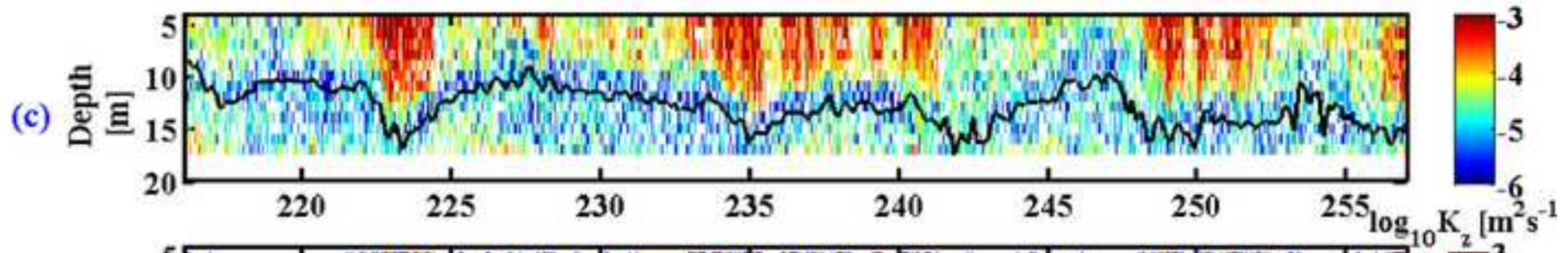

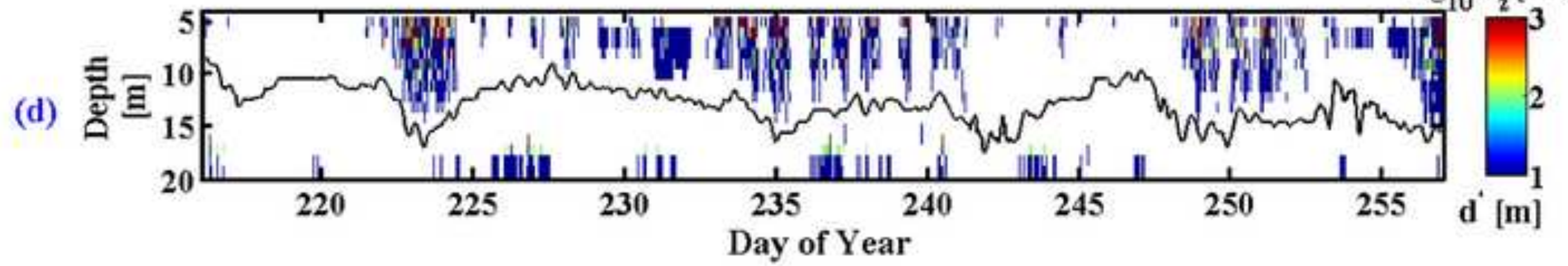




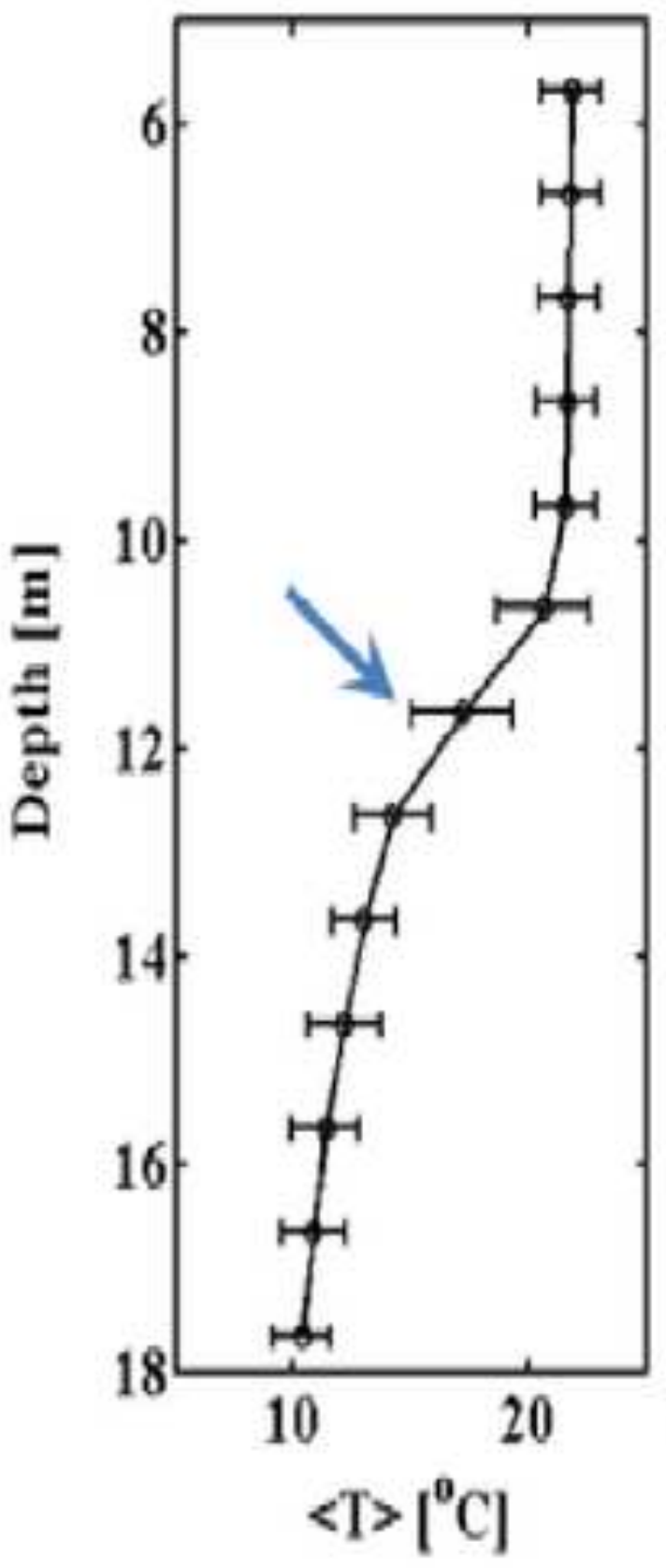

(a)

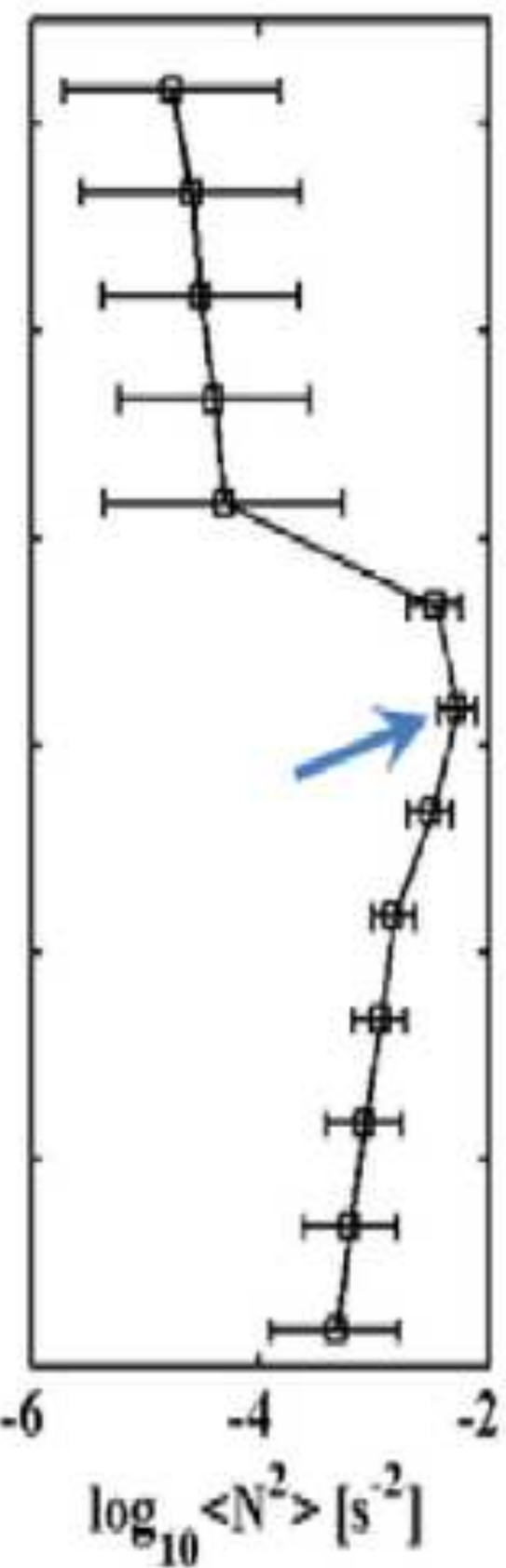

(b)

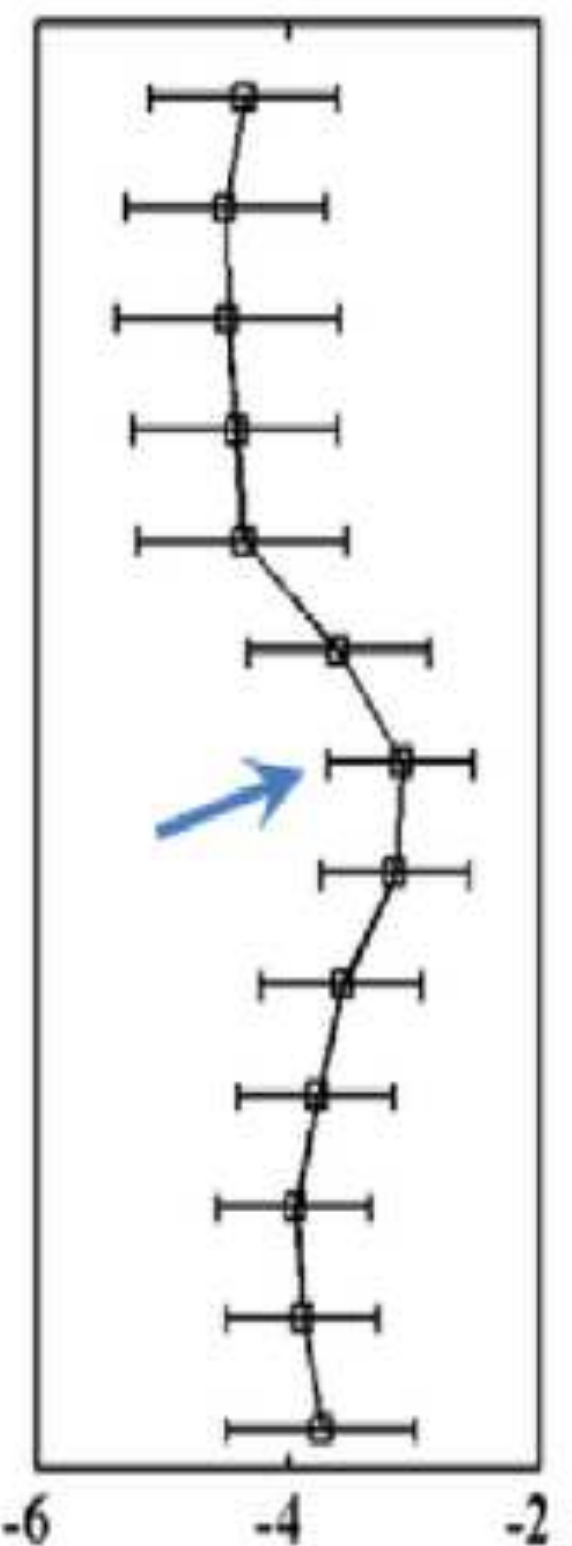

$\log _{10}\left\langle s^{2}>\left[s^{-2}\right]\right.$

(c)

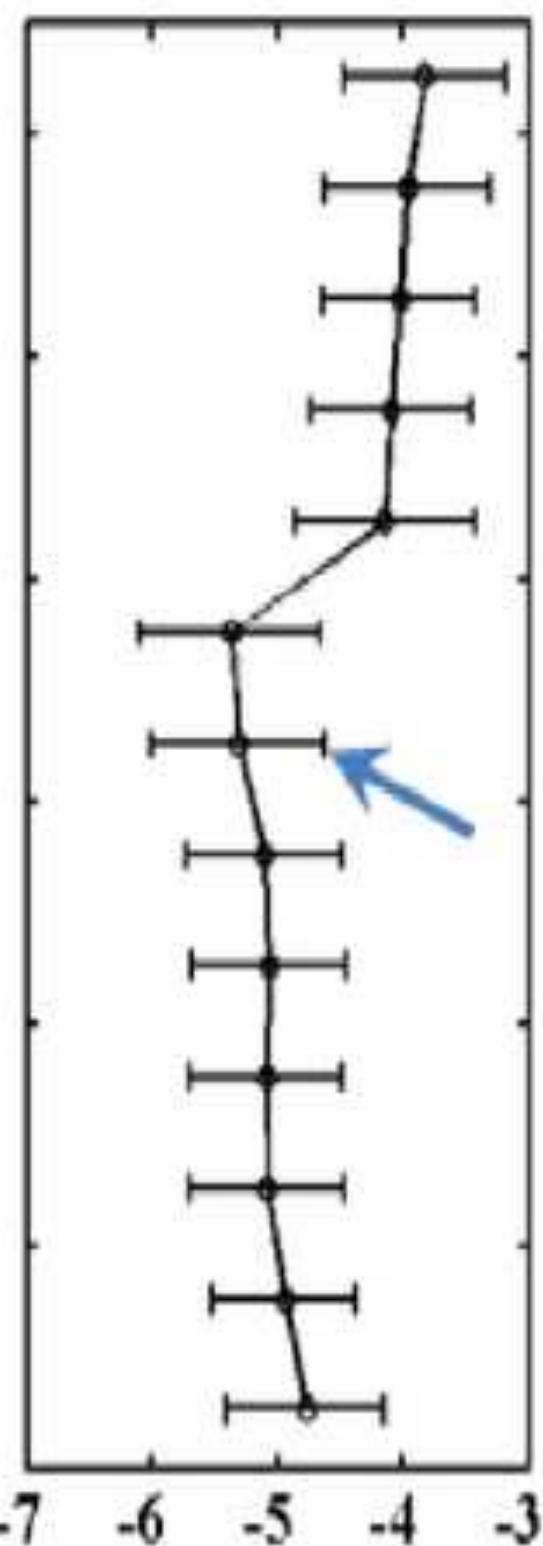

$\log _{10}\langle\mathrm{~K}\rangle\left[\mathrm{m}^{2} \mathrm{~s}^{-1}\right]$

(d) 
a)

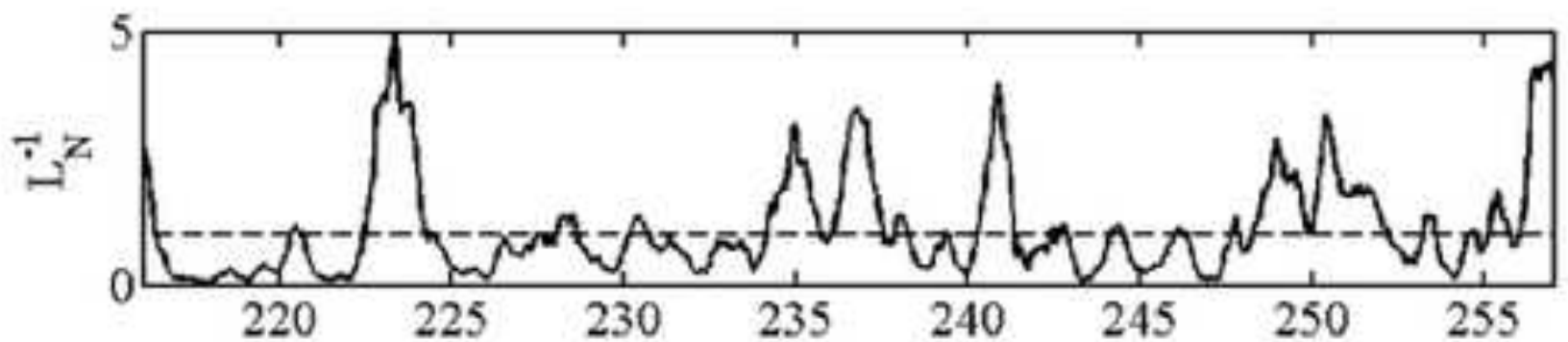

b)

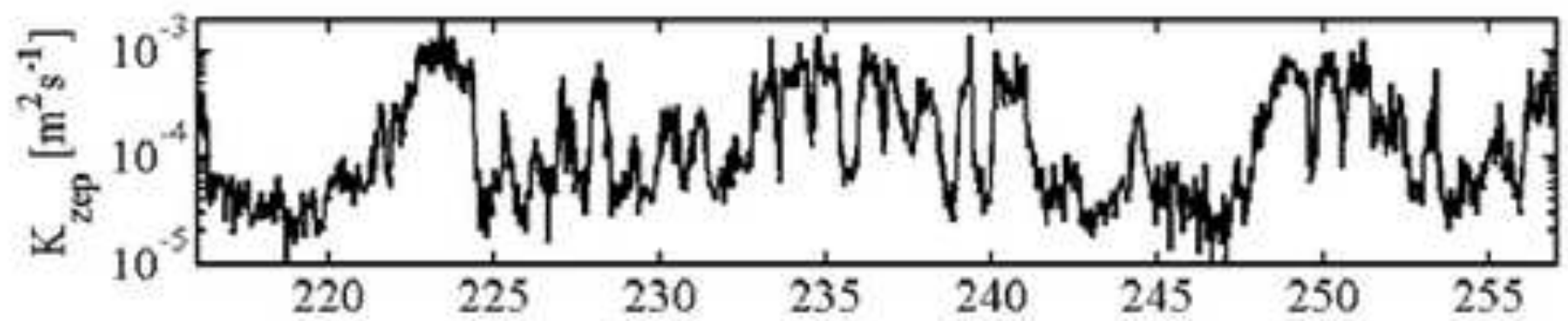

c)
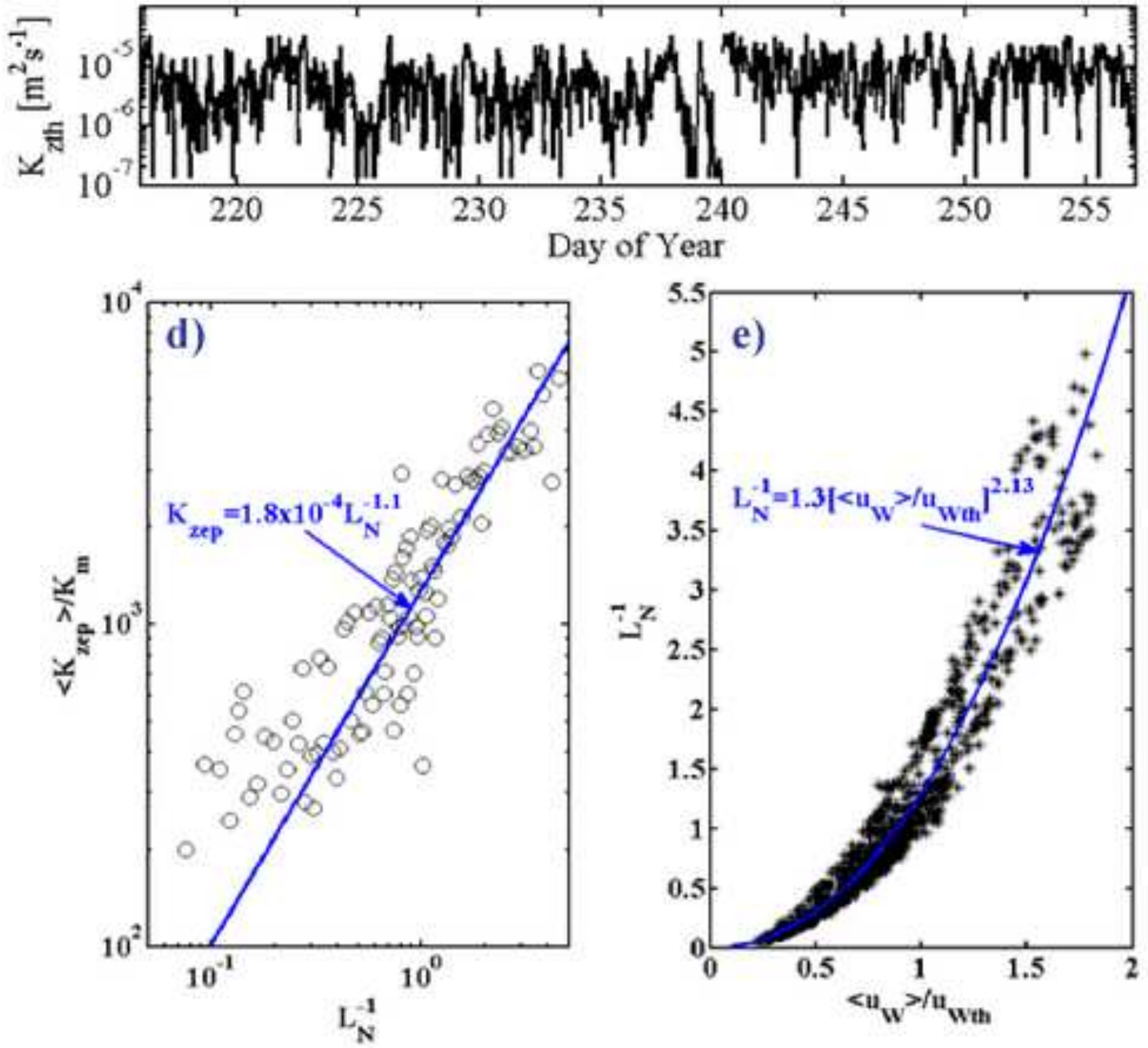
Click here to download high resolution image

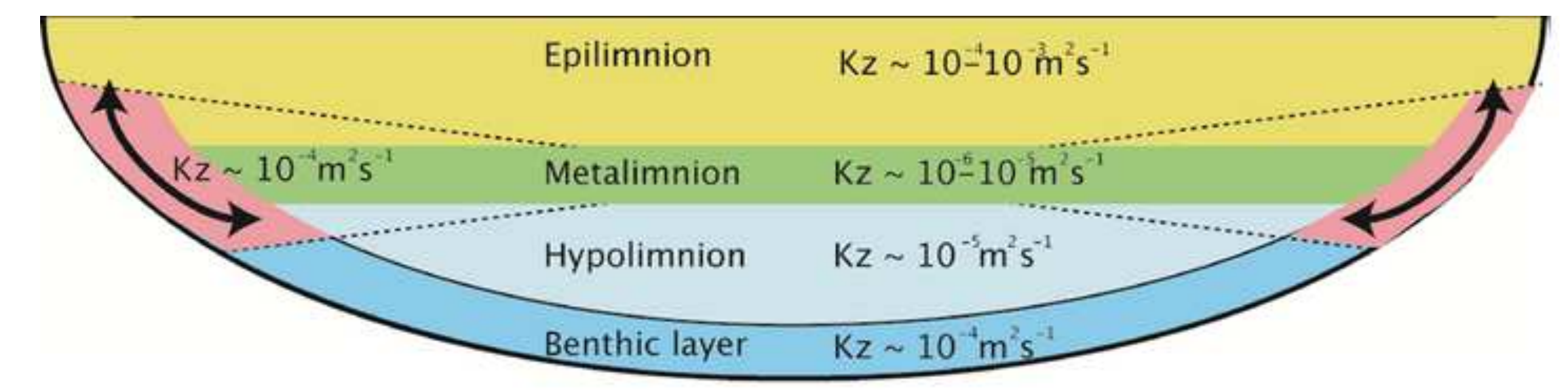

download high resolution image 


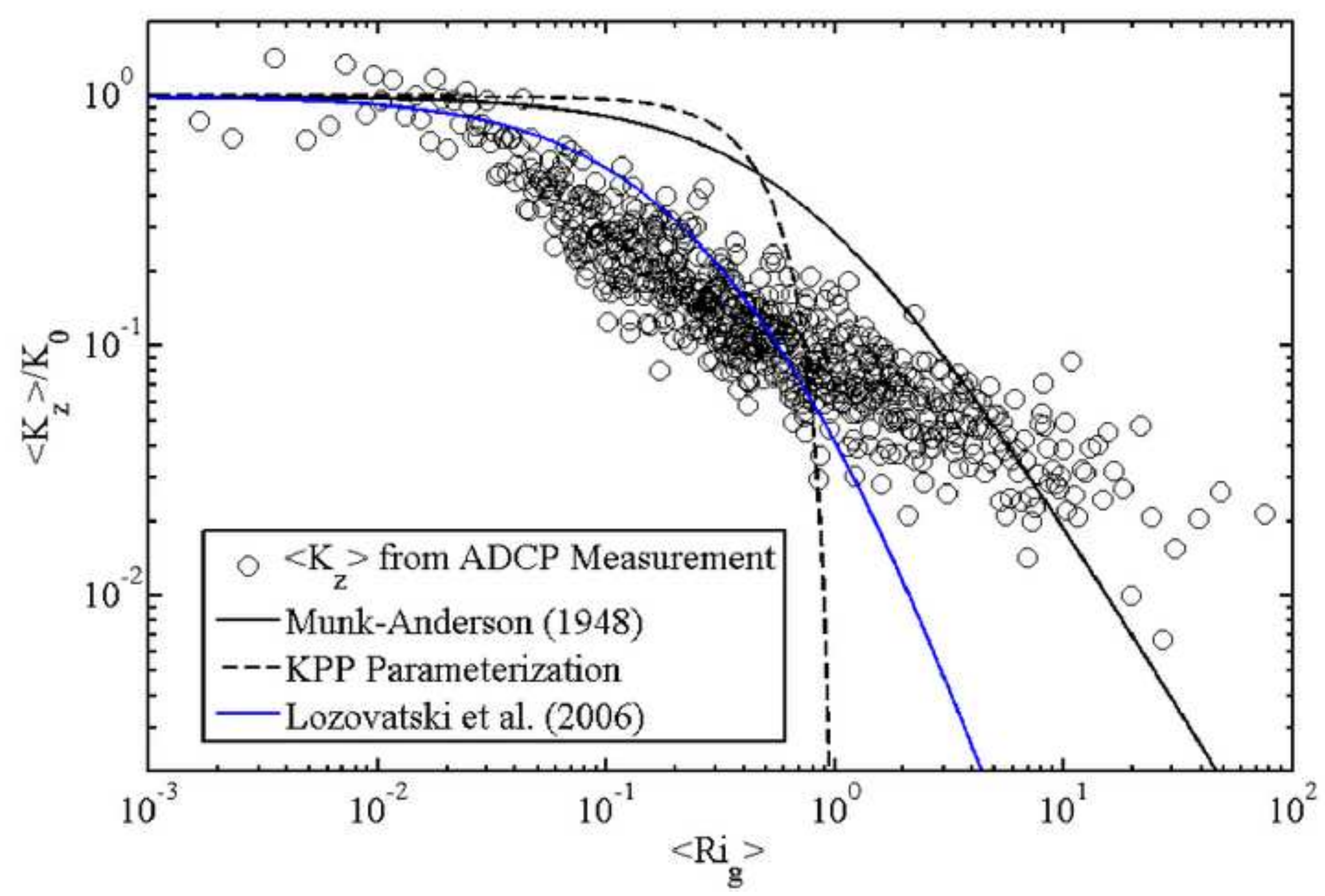



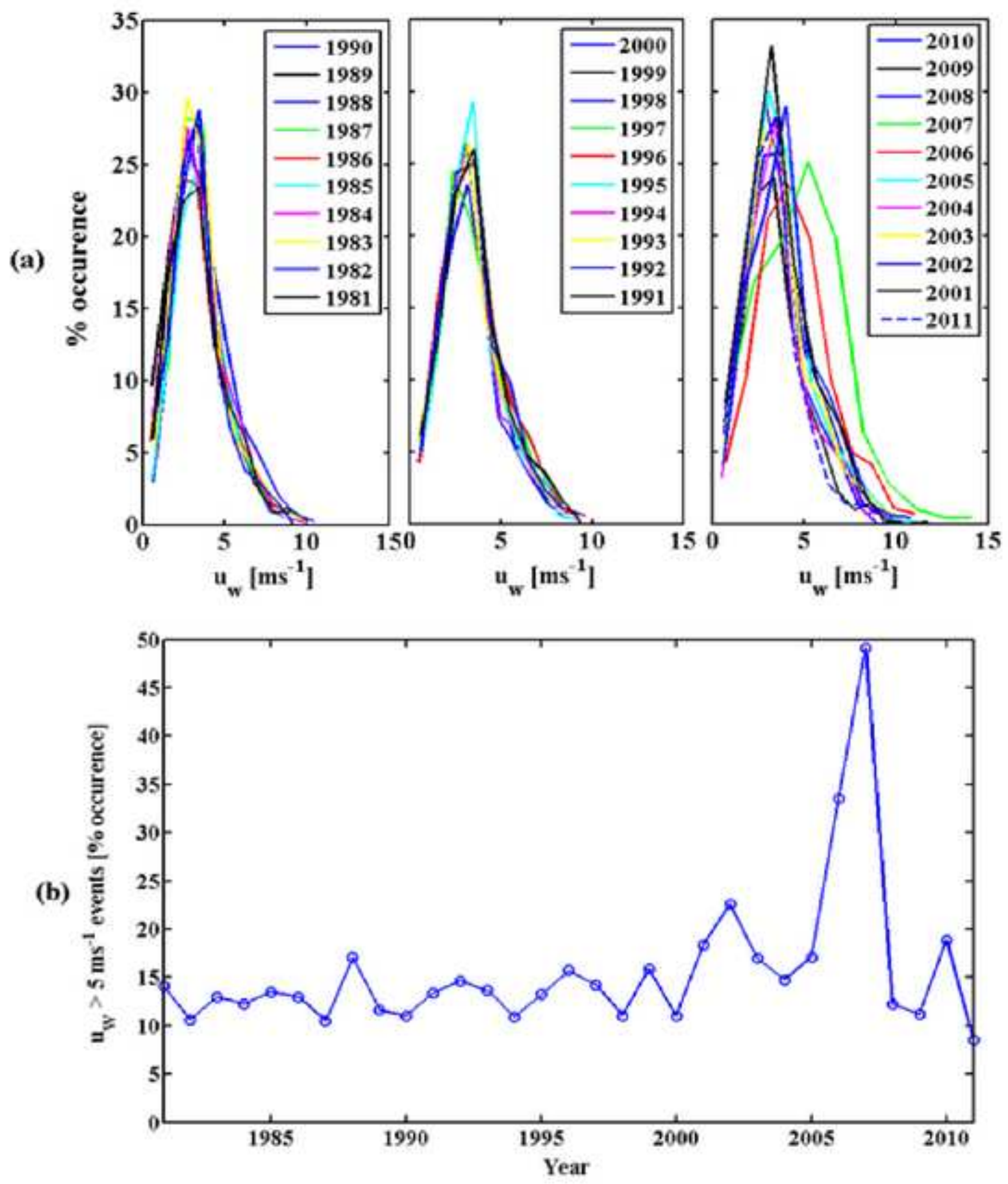
(a)

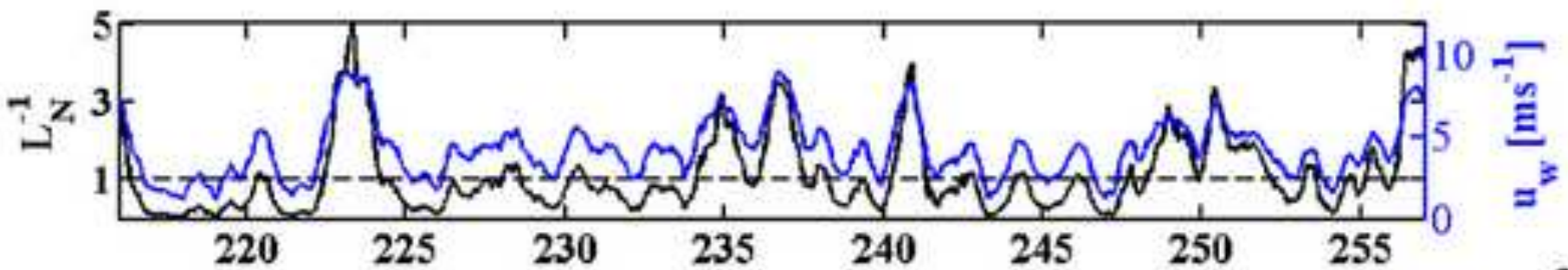

(b)

吾

E 5 पin

$250 \quad 255$
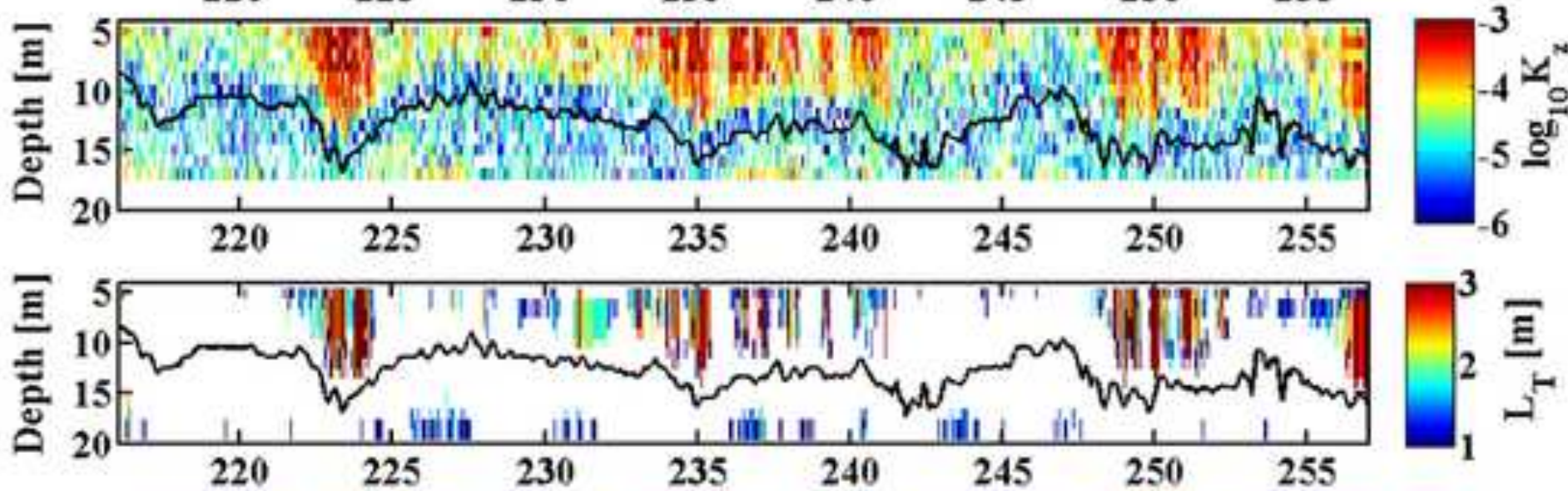

(c)

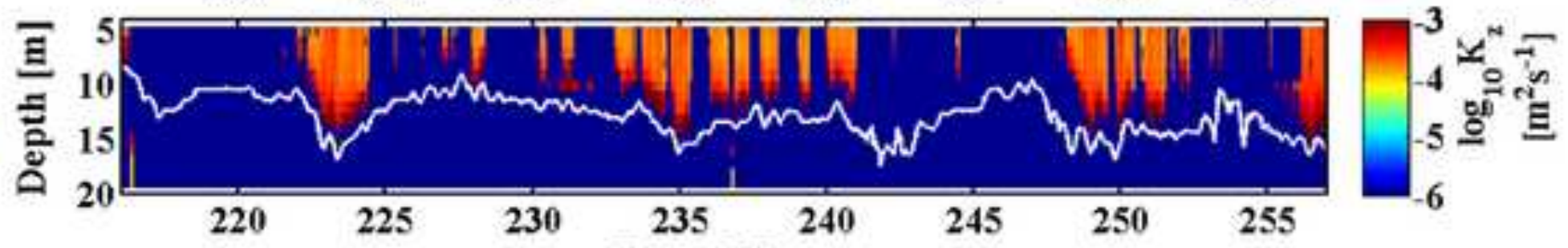

(e)

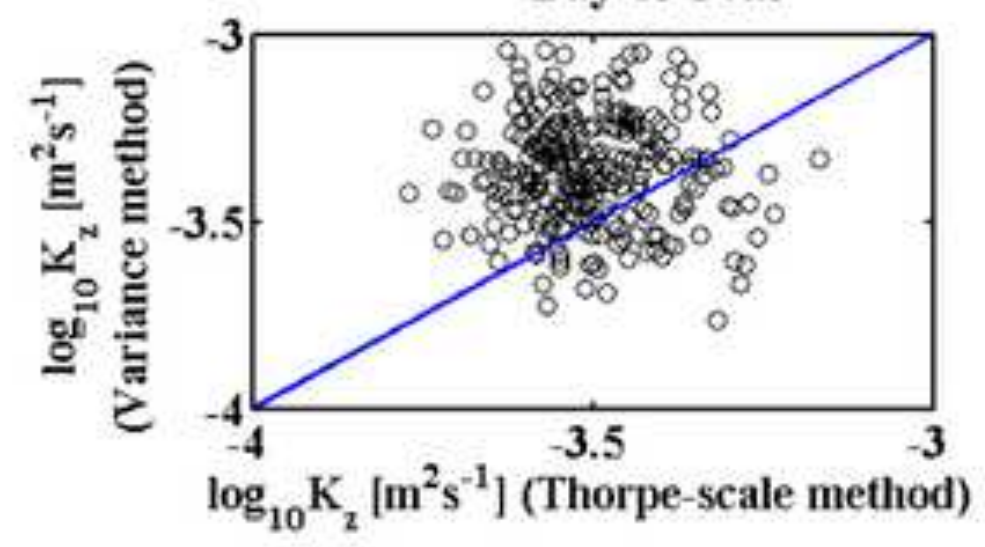



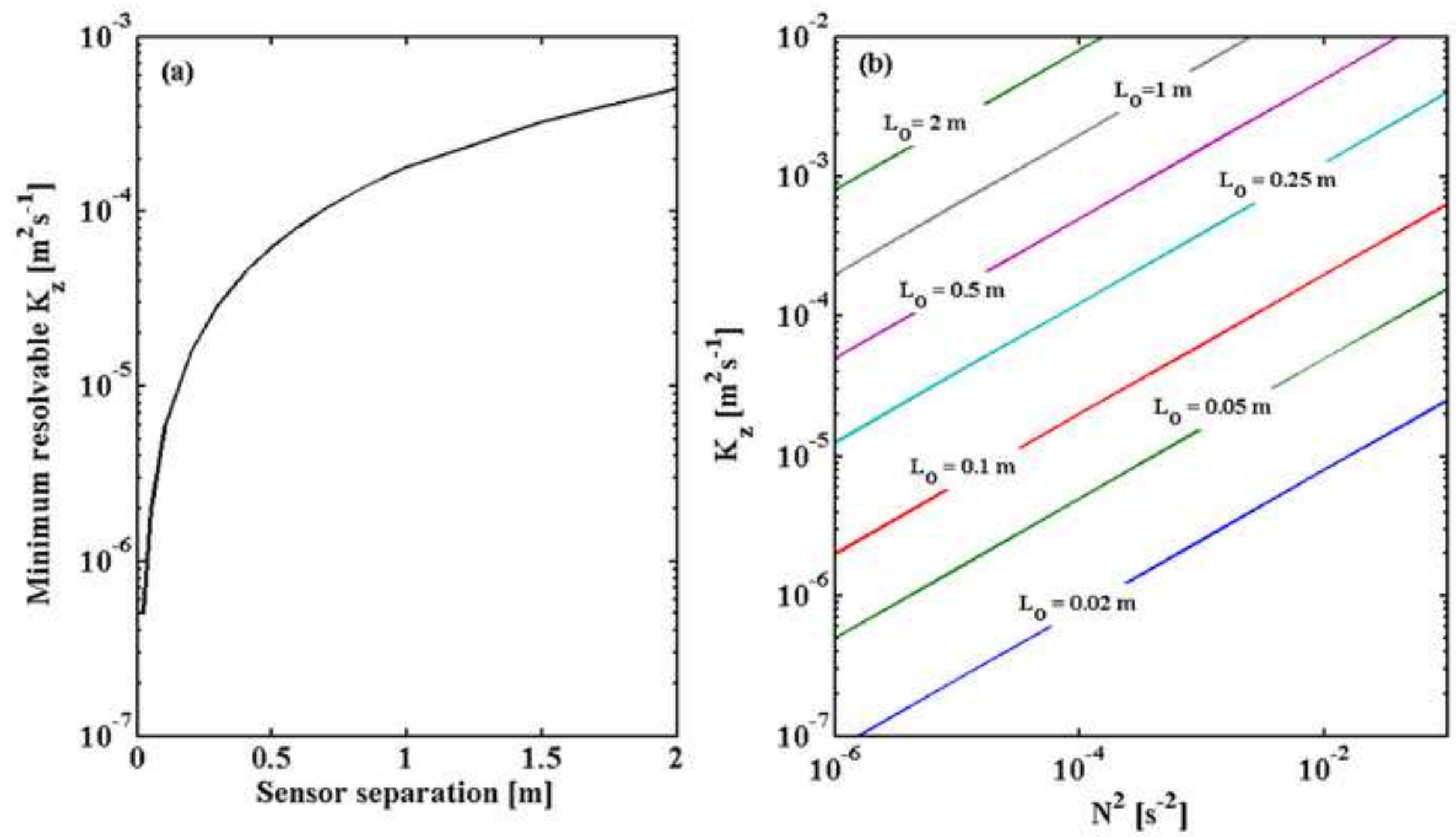